NBER WORKING PAPER SERIES

\title{
DIVERSIFICATION, INTEGRATION AND EMERGING MARKET CLOSED-END FUNDS
}

Geert Bekaert

Michael S. Urias

Working Paper No. 4990

\section{NATIONAL BUREAU OF ECONOMIC RESEARCH \\ 1050 Massachusetts Avenue \\ Cambridge, MA 02138 \\ January 1995}

We are grateful to Lewis Aaron at S.G. Warburg for generously providing data and many helpful conversations, and to the Miller Research Fund of the Graduate School of Business at Stanford University for financing the purchase of some of the data. We thank Campbell Harvey, Rober Hodrick, Jack McDonald, Peter Reiss, Bill Sharpe and Ingrid Werner for many useful comments and suggestions. Rohit Kumar provided computational assistance. Bekaert acknowledges the financial support of an NSF grant, and the Financial Services Research Initiative and the Bass Faculty Fellowship of the Graduate School of Business at Stanford. This paper is part of NBER's research program in Asset Pricing. Any opinions expressed are those of the authors and not those of the National Bureau of Economic Research.

(C) 1994 by Geert Bekaert and Michael S. Urias. All rights reserved. Short sections of text, not to exceed two paragraphs, may be quoted without explicit permission provided that full credit, including (C) notice, is given to the source. 


\title{
DIVERSIFICATION, INTEGRATION AND EMERGING MARKET CLOSED-END FUNDS
}

\begin{abstract}
Using an extensive new data set on U.S. and U.K.-traded closed-end funds, we examine the diversification benefits from emerging equity markets and the extent of their integration with global capital markets. To measure diversification benefits, we exploit the duality between Hansen-Jagannathan bounds [1991] and mean-standard deviation frontiers. We find significant diversification benefits for the U.K. country funds, but not for the U.S. funds. The difference appears to relate to differences in portfolio holdings. To investigate global market integration, we compute the reduction in expected returns an investor would be willing to accept to avoid investment barriers in six countries. We find evidence of investment restrictions for Indonesia, Taiwan and Thailand, but not for Korea, the Philippines or Turkey.
\end{abstract}

Geert Bekaert

Graduate School of Business

Stanford University

Stanford, CA 94305-5015

and NBER
Michael S. Urias

Graduate School of Business

Stanford University

Stanford, CA 94305-5015 


\section{Introduction}

The diversification benefits from exposure to emerging financial markets recently have attracted enormous attention among individual and institutional investors in the U.S and abroad. By some estimates, almost 90 billion dollars have flowed into the financial markets of developing countries since 1991, much of it in the form of closed and open-end mutual funds. Closed-end mutual funds, whose shares trade on an exchange different from the fund's assets, were the original vehicles for foreign investment in emerging financial markets. ${ }^{1}$

The distinguishing feature of closed-end funds is that fund share prices generally deviate from their portfolio value (known as 'net asset value' or NAV), and often trade at a premium when the assets are invested in closed or restricted markets. As a result, the returns from holding the fund shares may differ from those of the (possibly unattainable) portfolio in which the funds invest. The first objective of this paper is to formally assess the diversification benefits from holding the shares of closed-end funds investing in emerging markets and to compare them to the benefits from holding the emerging market indices. Our second objective is to use information on the differences between emerging market fund returns ancl net asset value returns to assess the degree of global capital market integration of emerging markets.

DeSantis [1993], Divecha et al. [1992], Harvey [1994] and other authors document sulystantial diversification benefits from investing in emerging equity market indices, but they ignore the high transaction costs and other constraints associated with investing in emerging equity markets. By contrast, a number of studies, including Bailey and Lim [1992], Urias [1992]. Bodurtha et al. [1993], Chang et al. [1993] and Diwan et al. [1993], cast douht on the diversification benefits from emerging market closed-end funds, but offer no formal assessment. The diversification gains from holding shares of closed-end fund portfolios can actually be achieved by foreign investors at relatively low cost when compared with holding emerging market shares directly:

To accomplish our first objective, we rely on the market-subset methodology developrel by De Santis [1992] and Snow [1992]. A set of asset returns provides diversification benefit. relative to a set of benchmark returns if adding these returns to the benchmark returns learls to a significant shift in the mean-standard deviation frontier. We characterize the economir

\footnotetext{
${ }^{1}$ For example, The Korea Fund, launched in 1984 and trading on the New York Stock Exchange, was thr. first financial vehicle through which foreign investors gained access to the horean stock market.
} 
importance of the frontier shift and we test its statistical significance using a mean-variance spanning test. The test exploits the duality between Hansen-Jagannathan [1991] bounds and mean-standard deviation frontiers of asset returns to derive the mean-variance spanning restrictions as a function of the marginal rate of substitution of representative investors. The test is robust to conditional heteroscedasticity and autocorrelation and can easily incorporate conditioning information. We propose a Wald test alternative to the likelihood ratio-type tests of DeSantis and Snow, and investigate the small sample properties of the two methods using Monte Carlo experiments.

The degree to which a particular market is integrated with global capital markets may have some bearing on the diversification potential of that market. Researchers generally. conduct tests of market integration using different assets from different markets, conditioning on an asset pricing model that may or may not account for investment restrictions. ${ }^{2}$ Bekaer and Harvey [1994] propose an alternative framework that accounts for time-variation in capital market integration using a regime-switching model. They document the difficulty in inferring the degree of capital market integration from the restrictions imposed in particular markets. Differences in the local and global pricing of equities have the potential to better describe the incidence and effectiveness of investment barriers. Hence, our second objective is to exploit the price segmentation inherent in country fund premia for information on the extent of global market integration for a number of countries.

We begin by specifying and estimating the discount factor which prices all traded assets in the U.S. and the U.K., including the emerging market funds. Using this discount factor we then estimate the expected return a global investor is willing to forego in order to avoid the investment barriers in individual countries. In effect, when investment barriers are binding except for the country funds, price segmentation may arise forcing investors to give up some of the diversification benefits from emerging markets.

Surprisingly, there have been few attempts to use country fund data to address questions. of market integration. Bonser-Neal et al. [1990] use event study methods to determine the impact of specific investment liberalizations on country fund premiums, while Diwan et al. [1992] and Eun et al. [1994] analyze country fund price segmentation in the context of static mean-variance models of fund prices when direct access to the local market is restricted to

\footnotetext{
${ }^{2}$ Examples of models that assume global integration are Harvey [1991] and Wheatley [1988]. Errunza and Losq [1985] and Stulz[1981], among others, propose models that specifically incorporate certain martiet frictions.
} 
some constant fraction of outstanding shares.

The richness of our data set makes our approach to diversification benefits and market integration feasible. Our tests are applied to a sample of over 40 U.S. and U.K. traded emerging market closed-end funds. We are able to compare the diversification benefits of U.S. and U.K. funds in light of measured differences in portfolio holdings. In our examination of market integration, we have typically several funds that target the same emerging market country or region, which should enhance the power of our tests. To control for the special features of closed-end fund pricing, we also carry out tests that use country funds investing in the equity markets of developed countries (what we call 'mature market' funds) and domestic funds (funds holding assets of the market where they trade) as benchmark assets. Hence we dd not take a stand on what explains the discounts on domestic closed-end funds (see, for example, Lee et al. [1991] and Bekaert and Urias [1994a] for potential explanations).

The main results of the paper can be summarized as follows. We find significant diversification benefits for the U.K. country funds, but not for U.S. funds. Holding the International Finance Corporation (IFC) Investable indices corresponding to the funds in our sample provides significant diversification gains. Using price and NAV information for funds targeting six countries, we find evidence of effective barriers to investment in Indonesia, Taiwan and Thailand, but not in Korea, the Philippines or Turkey.

Of conrse, since our analysis is based on an historical sample, the results may have no bearing on future performance. In particular, as the emerging financial markets covered in our sample move to increase accessibility and improve efficiency, diversification benefits may decline.

The remainder of the paper is organized as follows. Section 2 describes the data and some of the different characteristics of the U.S. and U.K. closed-end fund markets. Section 3 details the tests for mean-variance spanning and results from the tests. Section 4 presents our measure of market integration and applies it to the data, and Section 5 concludes.

\section{Data Description}

Table 1 summarizes emerging equity market fund assets at the end of 1991 and 1993. The last two years have seen a 300 percent increase in mutual fund assets invested in emerging equity markets. Recall that mutual funds can be characterized by their open or closed format. Unlike open-end mutual funds, closed-end funds issue a fixed number of shares that 
trade on an exchange, freeing portfolio managers from trading to meet net redemptions or net purchases of fund shares. The advantages of a closed format are especially relevant for funds investing in illiquid or volatile markets, and often local market regulations will favor the closed format early in the liberalization process. As Table 1 demonstrates, open-end fund assets have increased sharply in certain regions since 1991, but closed-end funds remain an important component of foreign capital invested in emerging financial markets. Closedend funds primarily trade on organized exchanges in the U.S., London and Hong Kong, and over-the-counter in London.

Table 2 contains some details of our sample of U.S. and U.K. closed-end funds. The sample consists of forty-three U.S. funds and thirty-seven U.K. investment trusts for the period beginning January 1986 through August 1993. Twenty-three of the U.S. funds and nineteen of the U.K. trusts are classified as emerging market funds, corresponding to the emerging markets defined by the IFC. The remainder of the funds in each group includes country funds investing in the securities of 'mature' markets as defined by inclusion in the FT-Actuaries World Indices, ${ }^{3}$ and a smaller group of closed-end funds that do not invest internationally. The sample attempts to include all emerging market U.S. funds and U.K. investment trusts with initial offerings prior to 1992 . In all but two cases, the entire trading history of the emerging market funds is included in the sample.

U.K. investment trusts are the equivalent of U.S. closed-end funds, but there are a number of institutional differences. While U.S. closed-end funds are required to distribute 90 percent of realized gains to shareholders in a given year to qualify for exclusion from corporation tax. investment trusts must retain capital gains for reinvestment. In addition, fund expenses are deductible from taxable income for U.K. trusts, but not for U.S. funds. British institutions are the primary holders of investment trusts, in part because of their inclusion in the FTAllshare Index, which is commonly indexed by large shareholders in Britain. ${ }^{5}$ U.S. closed-end funds, by contrast, are largely the realm of individual investors, although institutions make up a larger share of the ownership of emerging market funds than of country funds investing in mature markets. See Bekaert and Urias [1994a] for more details.

For each fund, the sample contains weekly price, NAV, exchange rate, dividend, and

\footnotetext{
${ }^{3}$ There are two exceptions. Mexico and Malaysia are part of the FT-Actuaries World Indices and the IFC: emerging markets. We classify them as emerging markets.

4The Mexico Fund and The Korea Fund, both listed on the NYSE, began trading prior to 1986.

${ }^{5}$ Table 2 details which funds in our sample are included in the FT-Allshare Index.
} 
volume information for the life of the fund. For the U.K. trusts, 'diluted' NAV and warrant prices are also included. It is customary in Britain to quote diluted NAV, which is the net asset value per share diluted to the level that would result if all outstanding warrants that are in the money were exercised immediately. Warrants trade for U.S. funds as well, but are much less common. Our analysis of NAV characteristics uses 'undiluted' NAV in all but five cases. ${ }^{6}$ The U.S. data was obtained from primary sources including Barrons and the CRSP database. Data on investment trusts was obtained from County NatWest Securities and S.G. Warburg.

Diversification benefits are measured in relation to a set of mature market benchmark returns. Individual country and regional total return indices for the mature markets were provided by Goldman, Sachs \& Co. $^{7}$ To assess the exposure of emerging market fund port folios to the local market, we use three weekly total return dollar indices available from the Emerging Markets Data Base (EMDB) maintained by the IFC. These include local market indices representing a broad cross-section of shares in each country, the IFC Global Indices representing a set of the largest capitalization and most liquid shares in a given country or region, and the IFC Investable Indices. The IFC Investable Indices represent a valueweighted subset of the equities in the IFC Global Indices for which ownership restrictions are not legally binding. The Investable Indices are better than the Global Indices as proxics for local market exposure that is actually attainable, and hence they are more relevant in comparisons with closed-end funds. Nevertheless, they only include assets satisfying cert ain liquidity requirements, and high transaction costs and other market frictions limit the effertive availability of investable shares. Additional details of the sample are contained in the Data Appendix

Table 2 also includes information about the average departure of prices from NAV (known as the premium) for each fund. This aspect of the 'closed-end fund puzzle' is well known for U.S. funds (see, for example, Lee et al. [1991] and Hardouvelis et al. [1993]). Ammer [1990] documents premium characteristics for U.K. investment trusts. The average premiums are $0.92 \%$ for the U.S. emerging market funds and $-9.51 \%$ for U.K. emerging market trusts. For the mature market funds, the numbers are $-7.09 \%$ for the U.S. and $-13.06 \%$ for the U.K.

\footnotetext{
${ }^{6}$ The five investment trusts in our sample for which only diluted NAV is available are indicated in Tahle 2.

${ }^{7}$ The FT-Actuaries World Indices (TM/SM) are jointly compiled by the Financial Times Limited, Goldman, Sachs \& Co., and County NatWest Securities in conjunction with the Institule of Actuaries and the Faculty of Actuaries
} 
For the U.S. funds investing in domestic securities, the average premium in our sample is $-8.25 \%$, and for U.K. domestic market trusts the average is $-14.64 \%$.

The premiums on closed-end funds, while potentially informative about market integration, could bias our tests for diversification benefits. If closed-end funds in the U.S. or the U.K. contain a fund-specific risk factor not spanned by the benchmark assets, our inferences could reflect only the gains from exposure to this factor and not the enhancement from emerging market assets added to the benchmark portfolios. We control for this possibility by using a sample of mature market and domestic closed-end funds from the U.S. and U.K. as the benchmark assets.

Finally, Table 2 lists the value of fund assets in April of 1993, the volatility of fund price returns, and a variance decomposition of fund returns showing the proportion of fund return variance due to NAV returns and premium change variance. The variance decomposition indicates that in the majority of cases, and in each fund category, the change in the log fund premium explains a larger share of price return variance than NAV returns explain. Hence the premium anomaly is clearly evident in the second moment properties of fund returns.

\section{Diversification Benefits}

\subsection{Mean-Variance Spanning}

We perform tests of mean-variance spanning based on the market subset methodology studied by DeSantis [1992] and Snow [1991]. The tests exploit the duality between HansenJagannathan bounds [1991] on investor marginal rates of substitution and the mean-standard deviation frontier of asset returns. They are related to the mean-variance spanning tests of Huberman and Kandel [1987] and Ferson et al. [1993] (see Appendix A).

We apply this test to the question of whether emerging market country fund returns are spanned by index returns from mature financial markets. Returns from the mature financial markets serve as the benchmark or spanning assets, and the emerging market fund returns are the test assets. The test assesses whether the leftward shift in the mean-standard deviation frontier is statistically significant.

We begin with the general conditional asset pricing restriction:

$$
E\left[\left(R_{t+1}+1\right) m_{t+1} \mid \Phi_{t}\right]=\iota
$$


where $R_{t+1}$ represent a vector of security returns, $m_{t+1}$ is an investor's marginal rate of substitution or discount factor, $l$ is the unit vector, and $\Phi_{t}$ is the information available at time $t$. The distinguishing feature of an asset pricing model is its specification for the discount factor, $m$.

Using the law of iterated expectations and equation (1), we can write the unconditional asset pricing restriction:

$$
E\left[R_{t+1} m_{t+1}\right]+E\left[m_{t+1}\right]-\iota=0 .
$$

Note that (1) and (2) assume frictionless markets and that the Law of One Price holds. The equality becomes an inequality if transaction costs are introduced (see Luttmer [1991]).

Hansen and Jagannathan [1991] show that the linear projection of $m_{t+1}$ onto the set of asset returns being priced has minimum variance in the class of all discount factors that satisfy (2). The discount factor $m_{t+1}^{\alpha} \equiv \alpha+\left[R_{t+1}-E\left(R_{t+1}\right)\right]^{\prime} \beta$, formed from the projection of $m_{t+1}$ onto one-period returns, then satisfies (2) and may be substituted for $m_{t+1}$ :

$$
E\left[R_{t+1} m_{t+1}^{\alpha}\right]+E\left[m_{t+1}^{\alpha}\right]-\iota=0
$$

Conditional on a value for $\alpha, m^{\alpha}$ can be used to place bounds on the standard deviation of random variables which satisfy the asset pricing equation for the asset returns $R$ since it is the minimum variance discount factor. From these bounds comes the duality with the mean-variance frontier of asset returns.

Now we can examine whether or not a subset of the assets to be priced, say the subiector $R_{t+1}^{1}$ from $R_{t+1} \equiv\left[R_{t+1}^{1 \prime}, R_{t+1}^{2 \prime}\right]^{\prime}$, prices all of the assets in $R_{t+1}$. Let there be $n_{1}$ returns in $R_{t+1}^{1}$, the benchmark returns, and $n_{2}$ returns in $R_{t+1}^{2}$, the test returns. If we restrict the $n_{2}$ coefficients $\beta_{2}$ on $R_{t+1}^{2}$ in equation (3) to be zero, we can test the overidentifying restrictions implied by (3):

$$
E\left\{R_{t+1}\left[\alpha+\left(R_{t+1}^{1}-E\left[R_{t+1}^{1}\right]\right)^{\prime} \beta_{1}\right]\right\}+\alpha-\imath=0 .
$$

Given a value for $\alpha$, there are $n_{1}+n_{2}$ moment conditions and $n_{1}$ parameters to estimate. hence there are $n_{2}$ overidentifying restrictions.

When a risk-free asset is known, the test is equivalent to a test that the mean-standard deviation frontier formed from the set of assets $R$ intersects the mean-standard deviation frontier formed from $R_{1}$ at the point with the highest Sharpe ratio. DeSantis [1993] proposes prespecifying two different values for a to test jointly for frontier intersection at two point- 
along the frontier. From two fund separation the test is equivalent to a test of mean-variance spanning. The sample moment conditions in the test for mean variance spanning are:

$$
h_{T}\left(\beta_{11}, \beta_{12}\right)=1 / T \sum_{t=1}^{T}\left\{\begin{array}{l}
\left\{R_{t+1}\left[\alpha_{1}+\left(R_{t+1}^{1}-E\left[R_{t+1}^{1}\right]\right)^{\prime} \beta_{11}\right]\right\}+\alpha_{1}-\imath \\
\left\{R_{t+1}\left[\alpha_{2}+\left(R_{t+1}^{1}-E\left[R_{t+1}^{1}\right]\right)^{\prime} \beta_{12}\right]\right\}+\alpha_{2}-\imath
\end{array}\right\}=0 .
$$

In the empirical work, we choose $\alpha_{1}$ to be the mean of one divided by one plus the conditionally riskless rate. Using the duality between mean-standard deviation frontiers of discount factors and asset returns, this choice for $\alpha_{1}$ enables us to approximate the change in the Sharpe Ratio for a given set of test assets. ${ }^{8}$ Hence we accompany the test results for diversification benefits with a measure of the economic importance of these benefits.

Consistent estimates for $\beta_{11}$ and $\beta_{12}$ can be computed analytically from (5) using a two-stage Generalized Method of Moments (GMM) estimator. Following Hansen [1982], an optimally chosen weighting matrix $W_{T}$ and sample moments $h_{T}$ are evaluated at second stagc estimates of $\beta_{11}$ and $\beta_{12}$. Define $b_{11}$ and $b_{12}$ to be the estimates. Then the quadratic form $T h_{T}\left(b_{11}, b_{12}\right)^{\prime} W_{T} h_{T}\left(b_{11}, b_{12}\right)$ has an asymptotic $\chi^{2}$ distribution with $2 n_{2}$ degrees of freedom under the null hypothesis that the coefficients on the test assets in the discount factors are equal to zero.

There are several advantages of the market-subset approach compared with the meanvariance spanning tests proposed by Huberman and Kandel [1987]. It allows us to easily. incorporate conditioning information for tests of conditional mean-variance spanning. The test does not require a distributional assumption on asset returns, and it is robust to general forms of conditional heteroscedasticity and autocorrelation. ${ }^{9}$

We incorporate conditioning information into our tests by scaling asset returns in equation (1) by variables in the information set at timet. Consider a vector of predetermined variables. $z_{t}$. Applying the law of iterated expectations, the moment conditions we exploit are:

$$
\left.E\left[\left(R_{t+1}+1\right) \otimes z_{t}\right] m_{t+1}\right]-E\left(\iota \otimes z_{t}\right)=0
$$

where $\otimes$ denotes Kronecker product. As with many of our tests, the conditional tests will

\footnotetext{
The approximation comes from the fact that we do not observe an unconditionally risk free rate. so li: Jensen's inequality we do not obtain the exact Sharpe Ratio using $\alpha_{1}$.

${ }^{9} \mathrm{Ferson}$ et al. [1992] propose a test of mean-variance spanning using GMM as a special case of a trat for latent variables.
} 
employ indices of fund returns for benchmark and test assets instead of individual fund returns. Let $z_{t}$ be the unit vector augmented by the index of individual fund premium changes (price returns minus NAV returns) corresponding to each index return in $R_{t+1}\left(z_{t}\right.$ has dimension $n 1+n 2+1)$. To keep the dimensionality of our test small, we consider a subset of the vector $\left(R_{t+1} \otimes z_{t}\right)$, taking only each return scaled by the unit vector and its own index of individual fund premium changes, which doubles the number of overidentifying restrictions in the spanning test to $4 n_{2}$. Scaled asset returns have been interpreted as managed portfolios by a number of authors. Many authors, including Thompson [1978] and Brauer [1988], have argued that U.S. closed-end fund discounts predict fund returns and can be used to construct abnormal portfolio returns.

\subsection{Test Statistics}

We can rewrite the orthogonality conditions (5) as

$$
h_{T}\left(b_{11}, b_{12}\right)=1 / T \sum_{t=1}^{T} f_{t}\left(b_{1}\right)=C_{T} b_{1}+d_{T}
$$

with

$$
\begin{gathered}
C_{T}=\left[\begin{array}{cc}
1 / T \sum_{t=1}^{T} R_{t+1}\left(R_{t+1}^{1 \prime}-E\left[R_{t+1}^{1 \prime}\right]\right) & 0 \\
0 & 1 / T \sum_{t=1}^{T} R_{t+1}\left(R_{t+1}^{\prime \prime}-E\left[R_{t+1}^{1 \prime}\right]\right)
\end{array}\right] \\
b_{1}=\left[\begin{array}{c}
b_{11} \\
b_{12}
\end{array}\right] \quad d_{T}=\left[\begin{array}{c}
\alpha_{1}\left[1 / T \sum_{t=1}^{T}\left(R_{t+1}+1\right)\right]-\imath \\
\alpha_{2}\left[1 / T \sum_{t=1}^{T}\left(R_{t+1}+1\right)\right]-\imath
\end{array}\right] .
\end{gathered}
$$

Conditional on the weighting matrix, $W_{T}$, the GMM-estimator is

$$
b_{1}=-\left[C_{T}^{\prime} W_{T} C_{T}\right]^{-1}\left[C_{T}^{\prime} W_{T} d_{T}\right]
$$

The weighting matrix is chosen to be a consistent estimate of the inverse of the spectral density at frequency zero of the orthogonal conditions, $S=\sum_{j=-\infty}^{\infty} E\left[f_{t} f_{i-j}^{\prime}\right]$. A popular 
estimate uses Bartlett weights (Newey and West [1987]):

$$
\widehat{S}=1 / T \sum_{t=j+1}^{T} \sum_{j=1}^{\rho}\left(1-\frac{j}{\rho+1}\right)\left[f_{t} f_{t-j}^{\prime}+f_{t-j} f_{t}^{\prime}\right]+1 / T \sum_{t=j}^{T} f_{t} f_{t}^{\prime} .
$$

Although the DeSantis test is easy to compute, many choices remain that could affect its small sample properties. Under the null hypothesis, $f_{t}$ should have zero mean and be serially. uncorrelated. Hence $\rho$ could be set equal to 0 in the expression for $\widehat{S}$. However, removing the mean of $f_{t}$ and allowing for some serial correlation in $\widehat{S}$ can improve the reliability of the estimators (see Cochrane [1994] for a general discussion). Furthermore, iterating on the weighting matrix might also improve the small sample properties of GMM-estimators (see Ferson and Foerster [1994]). In a Monte Carlo experiment described below, we examine 5 sub-statistics $M V_{i}(i=1 \ldots, 5)$. The properties of the different statistics can be summarized as follow:

\section{Test Statistics}

\begin{tabular}{|cccc|}
\hline Statistic & Demeaned & $\rho$ Correction & \# stages \\
\hline$M V_{1}^{\prime}$ & no & no & 2 \\
$M V_{2}$ & yes & no & 2 \\
$M V_{3}^{\prime}$ & no & yes & 2 \\
$M V_{4}$ & yes & yes & 2 \\
$M V_{5}$ & yes & yes & 7 \\
$M V_{w_{1}}$ & - & yes & 1 \\
$M V_{w_{2}}$ & - & no & 1 \\
\hline
\end{tabular}

To choose $\rho$ in the serial correlation correction, we use the "optimal bandwidth" procedure described by Andrews [1991]. In the applications below, we found that after 6 to 9 iterations in the GMM estimation, the weighting matrix changed very little.

Given our concern with small sample properties, we also investigate a Wald test, $M V_{11}$, as an alternative to the tests $M V_{i}(i=1, \ldots, 5)$. In the Wald test, the stochastic discount factor is a linear function of both the benchmark and test assets. The orthogonality conditions for the test are similar to equation (6), except that 


$$
\begin{aligned}
C_{T} & =\left[\begin{array}{cc}
1 / T \sum_{t=1}^{T} R_{t+1}\left(R_{t+1}^{\prime}-E\left[R_{t+1}^{\prime}\right\}\right) & 0 \\
0 & 1 / T \sum_{t=1}^{T} R_{t+1}\left(R_{t+1}^{\prime}-E\left[R_{t+1}^{\prime}\right]\right)
\end{array}\right] \\
& =\left[\begin{array}{cc}
\Sigma_{R} & 0 \\
0 & \Sigma_{R}
\end{array}\right]
\end{aligned}
$$

where $\Sigma_{R}$ is the variance-covariance matrix of the returns.

As Appendix A shows, there is a simple, analytical expression for $M V_{W}$. Let $A$ be a $2 n_{2} \times 2\left(n_{1}+n_{2}\right)$ matrix that selects the elements of the $2\left(n_{1}+n_{2}\right) \times 1$ vector $\beta$ that are zron under the null. Let $Q_{T}=C_{T}^{\prime} W_{T} C_{T}$. Then

$$
M V_{W}=T\left(A C_{T}^{-1} d_{T}\right)^{\prime}\left[A Q_{T}^{-1} A^{\prime}\right]^{-1}\left(A C_{T}^{-1} d_{T}\right)
$$

Hence, computation of $M V^{\prime}$ ' requires an estimate for $S$, but no multiple stage estimation is necessary. Moreover, since the GMM system is exactly identificd, the mean the orthogonality conditions is zero. We compute two Wald statistics, $M V_{w j}(j=1,2)$. For $j=2$, there is no serial correlation correction. For $j=1$, we construct $S$ using the optimal bandwidth procedure.

Appendix $B$ describes in detail a Monte Carlo experiment that examines both the size and power of the test statistics $M V_{i}^{\prime}(i=1, \ldots, 5), M V_{w^{\prime}},(j=1,2)$. In our bricf discussion here, denote the $n_{1}$ benchmark asset returns by $R_{t}^{1}$ and the $n_{2}$ test asset returns by $R_{t}^{2}$. The benchmark returns are assumed to follow a vectorautoregressive process with conditionally: heteroscedastic errors. The test asset returns are then a linear function of the benchmarh returus and an error term such that their mean and variance dynamics are completely driven by the benchmark returns and the mean-variance spanning restrictions are imposed. Thr model is estimated from the dat a and then used to generate samples of length 152 for $\left[R_{t}^{1}, R_{t}^{2}\right]$. on which the mean variance spanning tests are performed.

To investigate the power of the tests, we assume that an additional factor generates the test assect besides the benchmark assets. For the additional factor we use the JFC Investable Composite index return as a proxy for emerging market-specific risk (Section 2 describes thic index!. The alternative is calitrated so that the variance of the test assets explained hy the new benchmark is $20 \%$ higher than under the null. Details are provided in the Appendix.

The Nonte Carlo results. reported in Appendix B, are striking. Emploving a serial 
correlation correction according to the optimal bandwith schene of Andrews [1991]. but not de-meaning the orthogonality conditions, leads to dramatically superior size properties for $M V_{3}$. Although its power is weaker compared with some of the other tests, the relative loss in power is only significant for large GMM systems.

In general, both the size and power properties seem to deteriorate substantially as thic number of assets is increased. We conjecture that the saturation ratio (see Gallant and Tauchen [1991]) of the GMM system is the driving factor in the results. The saturation ratio is the total number of observations divided by the number of parameters to be estimated (including the parameters of the weighting matrix). When $n_{2} \geq 7$, the saturation ratio drops. below 10. Unfortunately, GMM-systems with such low saturation ratios are common in the empirical finance literature. In the empirical work to follow, we use the $M V_{3}$ statistic. with the caveat that the power may be weak when many test assets are included in the test. 


\subsection{Empirical Results}

In this section, we test whether adding emerging market assets to a number of different benchmark portfolios significantly shifts the investment opportunity set. Specifically, we examine the hypothesis of mean-variance spanning by testing whether the frontier of benchmark and test assets intersects the frontier of benchmark assets at two distinct points. In addition, we document the change in the approximate Sharpe Ratio corresponding to the shift in the mean-standard deviation frontier of asset returns when the test assets are added to the benchmark assets. The Sharpe Ratio measures the slope of the line from the riskless rate to the tangency portfolio on the efficient frontier, commonly known as the 'reward to risk' ratio (see Sharpe [1994]). It gives the largest mean return per unit of standard-deviation risk attainable for the assets in question. For a particular rejection of mean-variance spanning, the change in the Sharpe Ratio measures the economic importance of the shift in the efficient frontier.

Using the monthly IFC Global Indices and Morgan Stanley Capital International (MSCI) indices for mature markets, DeSantis [1993] finds that the frontier of IFC indices along with the U.S., European or World market portfolio does not intersect the frontier of the U.S. European or World market benchmark, but that the mature markets do intersect the frontier of the benchmark. Similarly, Harvey [1994] rcjects the hypothesis that the Global Indices and the mature markets intersect the frontier of all eighteen MSCI mature market indices. Both authors examine mean-variance intersection at only one point on the efficient frontier.

We compare the diversification benefits from emerging market closed-end funds with the benefits from holding the corresponding IFC, Investable Indices. ${ }^{10}$ As described in Section 2 , the IFC Investable Indice's correct for foreign ownership restrictions and exclude illiquicl stocks to some extent, but they do not account for other barriers to investment such as hight transaction costs or poor accouniting standards.

Recall that our test of mean-variance spanning produces a chi-square statistic with de-

\footnotetext{
${ }^{10}$ There are at least three index funds which allempt to malch the performance of the IFC Invcstahtr indices or some comparable. There is the open-end International Equity Index Fund Emerging Markets Portfolio managed by Vanguard Group, which tracks a Morgan Stanley index, a 'semi-open' fund managrd by the IFC tracking the IFC Investable Composite Index, and a closed-end fund, Baring Securities Emerging Market Index Tracker Fund, which trades over-the-counter in London and tracks an index published hy Baring Securities. Of course, an investor could buy the stocks in the index directly at some nontrivial coct A comparison between holding pertfolios of country funds and holding investable indices presumes that thr. marginal investor in country funds can obtain the theoretically investable portfolios.
} 
grees of freedom equal to two times the number of overidentifying restrictions when we impose the restriction that a set of test asset returns and benchmark returns is priced by the subset of benchmark returns. The following table summarizes the test assets we examine in Tables 3 and $5 .^{\prime \prime}$ In all cases, we report the probability value for the mean-variance spanning test statistic $M V_{3}$, which incorporates a serial correlation correction but no demeaning of the sample moment conditions, and 2 stages in the GMM estimation. Where available we also report the probability value according to the empirical distribution under the null.

Mean-Variance Spanning Tests

\begin{tabular}{|lc|}
\hline Test Assets & $n_{2}$ \\
\hline U.S. Emerging Market Funds & 12 \\
-Corresponding IFC Investables & 12 \\
U.K. Emerging Market Trusts & 7 \\
-Corresponding IFC Investables & 7 \\
U.S. \& U.K. Funds Emerging Market Funds & 19 \\
U.S. Emerging Market Fund Index & 1 \\
-Corresponding IFC Investables Index & 1 \\
U.K. Emerging Market Fund Index & 1 \\
-Corresponding IFC Investables Index & 1 \\
U.S. \& U.K. Emerging Market Fund Indices & 2 \\
\hline
\end{tabular}

The first set of benchmark assets cousists of the FT-Actuaries World Index for the L.S.. the U.K., Europe excluding the U.K., and the Pacific. The benchmark was chosen to represent the portfolio of a globally diversified investor in 1990, the start of the test period. Most combinations of individual country indices are spanned by this benchmark. The tees period was chosen to maximizc the number of funds included in the tests.

Table 3, Panel 1 presents results from mean-variance spanning tests where we restrict investors to hold only funds which have corresponding IFC Investable indices, and only onc fund for a particular country or region if there are multiple such finds, to enhance the power

\footnotetext{
"Note that the countries and regions covered by the set of U.K. emerging market trusts is a subset of those covered by the U.S. funds.
} 
of our tests. ${ }^{12}$ In our discussion, we will use $5 \%$ as the size of the test. Given that the power of our tests ranges between $13 \%$ and $73 \%$, readers concerned about Type-2 errors may wish to employ a higher size. We fail to reject mean-variance spanning for the twelve individual U.S. emerging market funds. The test statistic falls within the third decile of the empirical distribution under the null. We also fail to reject spanning at the five percent level using all nineteen funds. However, we do reject strongly mean-variance spanning for the seven individual U.K. emerging market funds, according to both the chi-square distribution and the null empirical distribution at the $5 \%$ level.

The same tests were performed using equally-weighted indices of country fund returns. reducing the dimensionality of the problem considerably. We fail to reject spanning for the U.S. fund index at the five percent level, but we reject spanning for the U.K. fund index and the two indices together using the chi-square and empirical distributions.

It is possible that closed-end fund industry factors could affect the results. If the test asset returns contain a closed-end fund-specific risk factor not spanned by the benchmark FT-Actuaries returns, our tests could produce rejections of mean-variance spanning which do not reflect international diversification benefits. Since we are interested in whether emerging market funds provide diversification benefits relative to a worldwide mature market portfolio, we wish to control for closed-end fund effects. To do so, we construct a set of benchmark equally-weighted index returns from domestic closed-end funds and mature market country funds. This controls for the presence of closed-end fund-specific factors in the U.S. and the U.K. while providing a benchmark of mature market assets similar to the FT-Actuarics benchmark. It turns out that the closed-end fund benchmark spans the FT-Actuaries benchmark, but not vice versa.

Panel 1 of Table 3 reports test results using the control benchmark. We again fail to reject mean-variance spanning for the twelve U.S. funds and for the U.S. fund index. The rejection for the U.K. fund index and the U.S. and U.K. fund index together no longer holds. but we stil reject spanning for the seven individual U.K. emerging market funds using the chi-square and the empirical distribution under the null. Overall, the results from Panel 1 suggest that the individual U.K. emerging market funds together provide diversification benefits relative to the benchmark portfolios. Apparently, constructing an index of these funds changes the distribution of returns so that they no longer provide such benefits. Using

\footnotetext{
${ }^{12}$ Choosing alternate funds from the same market does not change any of the results.
} 
an equally-weighted index could bias the results against finding diversification benefits if the index is not efficient in the space of test asset returns. In fact, the results are not materially different when we use value-weighted indices, except that we can reject meanvariance spanning for the index of U.S. funds using the control benchmark. ${ }^{13}$ This result appears to be due to large weights on $\mathrm{MXF}$ and $\mathrm{KF}$ during the test period.

To assess whether our results are robust to the currency in which returns are expressed, we performed tests with the U.S. and U.K. funds expressed in British pounds. Using the closed-end fund benchmark, the rejection for the seven U.K. funds remains using the chisquare distribution and the empirical distribution computed in dollars. As before, there are no other rejections for fund indices or individual U.S. funds.

Table 3, Panel 2 presents results from mean-variance spanning tests for the IFC Investable Indices corresponding to the test funds. The U.S. Investables are the individual IFC Investable indices corresponding to the countries and regions covered by the U.S. funds. and the U.S. Investables Index is the equally-weighted index of those index returns. For both the FT-Actuaries and the control benchmark, we can reject strongly mean-variance spanning for the individual IFC indices corresponding to the U.S. and U.K. emerging market funds using the chi-square distibution under the null. When we construct their equally-weighted indices, we can still reject the spanning hypothesis at the five percent level. These rejections remain valid using the empirical distribution generated for Panel $1 .{ }^{14}$ It is notable that we obtain a rejection of the spanning hypothesis for the indices corresponding to the U.S. funds. while we were unable to reject the hypothesis using the funds themselves. It appears that the Investable indices offer superior diversification benefits compared with the U.S. emerging market funds. Of course, there are considerable costs associated with obtaining the index performance relative to the costs of holding the funds.

The economic impact of differences in performance for the U.S. and U.K. funds and the IFC Investable indices is represented by the change in the Sharpe Ratio that accompanies each test. For example, the rejection of mean-variance spanning for the individual U.K. funds and the control benchmark (Table 3, Panel 1) is associated with a Sharpe Ratio change of about 0.096 . By contrast, the rejection for the corresponding IFC indices (Table 3, Panel

\footnotetext{
${ }^{13}$ The value-weighted indices are constructed using the value of individual fund assets in dollars in April. 1893 (see Table 2).

${ }^{14}$ There is no reason to expect the empirical distribution to be substantially different for the statistics generated with the IFC indices as test assets.
} 
2 ) is associated with a Sharpe Ratio change of 0.28 . This difference indicates that the slope of the line with intercept (approximately) at the mean of the conditionally riskless rate and tangent to the efficient frontier becomes three times more steep when the IFC indices are included with the benchmark than when the U.K. funds are included with the benchmark.

What explains the performance differences between U.S. and U.K. funds? First, since the U.S. sample covers emerging markets not included in the U.K. sample, the results could reflect in part the different composition of the samples. In fact, using the control benchmark and seven U.S. funds corresponding to the U.K. coverage, we still fail to reject spanning using the chi-square distribution and the empirical distribution for the seven asset casc. Again, this result is robust to the funds we choose when there is duplicate coverage, and to the benchmark used. When we exclude the global and regional emerging market funds from each sample (leaving four single-country funds in the U.S. and the U.K.), we reject spanning for the U.K. funds but not for U.S funds. Figure 1 plots the mean-standard deviation frontiers of the U.S. and L.K. funds with common coverage (scven in each market), and the IFC Investable indices covered by the funds, with both benchmarks. While standard errors are associated with each of the fronticrs, the fronticr formed from the U.K. funds and thr benchmark assets appears well to the left of the frontier formed from the U.S. funds.

A second possible explanation relates to differences in managerial skill. These difference could be reflected in the $\mathrm{NAV}$ compositions of two funds investing in the same market. or in the market timing abilities of different managers. Our framework is not suitable to investigate market timing ability, but we can address differences in fund portfolio risk exposure. Talsle 4 contrasts the portfolio exposurc of U.S. and U.K. funds that invest in the same emergins market or region during the test period. The table presents the risk exposure of each fund's NAV to the local market index, the IFC Global index, and the IFC Investable index, as the coefficient from a multivariate regression of $\mathrm{NAV}$ returns on the returns of the indices. ${ }^{15} \mathrm{Th}$ residual from a linear projection of the local market index and the IFC Global index return onto the IFC Investable index return represents the component of those returns uncorrelaterl with the IFC Investable index, $r^{L \cdot I}$ and $r^{G \cdot I}$, respectively. The results clearly suggest that the risk exposure of U.K. and U.S. funds investing in the same emerging market differs. For example, $\beta_{G . I}$ for the U.S. funds investing in Indonesia (IF and JGF) is less than 0.2. whilr.

\footnotetext{
${ }^{15}$ Note that nontrading problems could affect the consistency of our estimates of risk exposurc to $1 \mathrm{l}$, indices. In addition, dynanic trading strategies by fund managers might reduce the explanatory power of the indices.
} 
for the U.K. fund JAVA, $\beta_{G . I}$ is 1.226 and significant. However the sensitivity of the U.S. Indonesian funds to the IFC Investable is greater than that of JAVA, 0.454 and 0.481 versus 0.269. The index returns explain a large share of the variation in NAV returns for most funds, as indicated by $\overline{R^{2}}$. The results in Table 4 suggest that the superior diversification benefits from U.K. emerging market funds could arise from portfolio selection.

Table 5 reports results from conditional mean-variance spanning tests using the control benchmark of domestic and mature market funds and emerging market fund indices as the test assets. Recall that we scale each index return in the benchmark and test asset.s by the unit vector and its oun index of individual fund premium changes (price minus NAV returns), which doubles the number of overidentifying restrictions in the spanning test to $4 n_{2}$. Interestingly, we reject spanning for the scaled U.S. fund index as well as the scaled index of U.K. funds, and for the U.S. and U.K. fund indices together, using the chi-square distribution. Apparently fund premium changes predict all fund returns in our sample and induce diversification gains for U.S. funds not present from holding only the funds themselves.

In sum, results from unconditional mean-variance spanning tests for U.S. and U.K. emerging market funds indicate that there are diversification benefits from holding the individual U.K. emerging market funds. Constructing an index of emerging market funds appears to weaken the benefits from the U.K. funds. The results do not change when we control for closed-end fund-specific factors, and they are robust to the currency in which we express returns. By contrast, the IFC investable indices corresponding to the U.K. and the U.S. funds provide unequivocal diversification benefits. While the U.S. funds appear to perform poorly compared with the smaller set of U.K. funds, the NAV composition of U.S. and U.K. funds investing in the same market seems to be quite different. The use of conditioning information leads to diversification benefits for the U.S. as well as the U.K. funds.

\section{Market Integration}

\subsection{Price Segmentation}

\subsubsection{Framework}

Despite recent capital market liberalizations, most emerging equity markets are not con pletely integrated in global capital markets. Investment restrictions of various forms persist 
and poor liquidity or political risk often serve to effectively segment emerging markets from world markets (sec Bekaert [1994] for a detailed analysis). As Bekaert and Harvey [1994] stress, the degree to which a national capital market is integrated with world capital markets is very difficult to measure. Looking at investment restrictions is problematic because there are numerous types of restrictions with some being more important than others in different countries. In addition, statutory investment restrictions may not be binding.

Our data on country funds offer a unique opportunity to measure the effective degree of market integration. With closed-end funds we observe two prices for the same assets: fund price and NAV. All other things constant, binding investment restrictions will raise the pricc of a fund's shares relative to its net asset value by approximately the amount the marginal investor is willing to pay to aroid these restrictions. This intuition was used by BonsrrNeal et al. [1990], who tested whether announcements of changes in investment restrictions were related to changes in the price/NAV ratios of funds investing in those countries. The! document significant decreases in fund premiums following announcements of investment liberalizations.

The main purpose of this section is to develop a measure of market integration that exploits the apparent price segmentation between funds and NAVs. The measure we propose can be interpreted as the reduction in expected return a representative world investor would be willing to suffer in order to obtain barriers-free exposure to emerging equity markets. We will compute this measure for six countries: Indonesia, Korea, the Philippines, Taiwan. Thailand and Turkey.

Our framework builds heavily on the rational asset pricing framework used to test for diversification benefits. As will become clear below, we are able to control for the closed-end fund puzzle in our computations. Domestic funds also trade at prices that differ from their net asset values and discounts vary both across funds and over time. Hence, country fund premiums and discounts cannot solely be due to investment restrictions. It is important to note that some researchers have claimed that the behavior of premiums on country funds defies rational explanations. Indeed, the empirical facts seem puzzling at first sight. Country fund returns show high positive correlation with the trading market (see Bailey and Lim [1992], Diwan et al. [1993] and Bekaert and Urias (1994b]), and Hardouvelis et al. [1991] find a large common component in the premiums on country funds. This is true despite the fact that the funds invest in equity markets whose returns show low correlation with U.S. returns. This has motivated Bodurtha et al. [1993] and Hardouvelis et al. [1993] to claim 
that country fund premiums are primarily driven by investor sentiment.

On the other hand, Diwan et al. [1992] and Eun et al. [1993] explore the effect of investment restrictions on country fund pricing in the context of static mean-variance models. When the underlying assets of the fund are not spanned by the world assets and crossborder arbitrage is not possible, country fund premiums can arise in these models. The main variables driving premiums are the different degrees of risk aversion in the local and world markets and the different portfolios against which systematic risks are measured in the world and local markets. Note that to prevent arbitrage, the local investors must also be prevented, for example, from freely short-selling U.S.-traded country funds and buying local stocks. ${ }^{16}$

Rather than using a fully specified model, we base our measure directly on the intertemporal relationship between stochastic discount factors and asset returns that underlies our spanning tests in Section 3. Consider a world in which arbitrage between country funds and the underlying assets is diffcult and costly. If the markets are effectively segmented, world investors will price the country funds, whereas local investors will price the local assets. Both the fund and the underlying assets are claims to identical cash flows. Hence, the difference between local and global pricing can be completely described by the differences in the pricing kernels that price net asset values and country funds, respectivcly.

Time-variation in these discount factors can explain some of the salient features of country fund premiums described above. For example, a rise in U.S. interest rates may decrease discount factors in world capital markets, without much effect on discount factors in segmented markets. This in turn leads to lower fund prices for all country funds, without much of an impact on NAVs. Hence, one potential measure of market integration could be based on the difference between the stochastic discount factor that prices country funds in the trading market and the discount factors that price the assets of the funds, used by local investors. ${ }^{17}$ Recall that the fundainenlal asset pricing equation (1) places no restrictions on the form of the discount factor. We assume that the stochastic discount factors are linenr functions of a limited number of benchmark returns. ${ }^{18}$ Unfortunately, we cannot identify

\footnotetext{
${ }^{16}$ Of course, since such arbitrage will likely involve costs and since there is no guarantee that country fund prices will actually return to their net asset value, it may not be truly risk free (se Tuckman and Yila [199.3] for a formal model).

${ }^{17}$ This is in fact the basic idea behind the non-parametric measure of market integration developed hy Chen and Knez [1994].

${ }^{18}$ Bansal et al. [1993] study the properties of non-linear pricing kernels in an international setting.
} 
the discount factor that prices local assets. The net asset values of the country funds in our sample are not spanned by local indices. Portfolio managers clearly do not index the local indices in our dataset (see also Table 4). However, we can identify the discount factor (pricing kernel) that prices world assets, including country funds.

Define the discount factor pricing country fund returns to be

$$
m_{t+1}^{T}=\alpha^{T}+\left(R_{t+1}^{B T}-E\left[R_{t+1}^{B T}\right]\right)^{\prime} \beta^{T}
$$

where $R_{B T}$ denotes a benchmark of investable assets. We identify $\alpha^{T}$ as the mean of one divided by one plus the conditionally riskless rate. The conditionally risk free rate is measured as the one week dollar LIBOR ratc. As benchmark assets, we use the closed-end fund control benchmark and a mimicking portfolio for the IFC Investable Composite index construrted from global funds trading in the U.S. and the U.K. ${ }^{19}$ Hence, we control for the presence of possible closed-end fund-specific pricing factors by including closed-end fund returns in the benchmark assets for fund returns. The mimicking portfolio for the IFC Investable Composite is constructed by forming the weighted sum of returns on the global closed-end funds that spans the IFC index. These weights are computed using the fact that when mean-variance spanning holds, the test returns can be written as a linear function of the benchmark return with the coefficients summing to one (see also Appendix A).

Ideally, this benchmark should span all individual country fund returns. Since there are a total of 16 funds investing in the six countries of interest, it is impossible to test this hypothesis in a meaningful way. Instcad, we impose the weaker requirement that the benchmark prices six indices of the individual country funds for our six countries. We cannot reject that our benchniark spans the six NAV value-weighted indices of fund returns representing each country. The benchmark also spans the set of local index-mimicking portfolios of fund returns. These mimicking port folios are constructed from the spanning weights for the IFC' Investable index in each country using the individual NAV returns as benchmark assets. The resulting portfolio can lo interpreted as that portfolio of individual country funds with exposure closest to the IFC Investable index. ${ }^{20}$

\footnotetext{
19The global emerging market funds used to span the Investable Composite are EMF, ABTST, BCFM and TMPLT. These funds may invest in any emerging market.

${ }^{20}$ This interpretation remains valid when mean-variance spanning is rejected, as it is for a number of countries. Note that we do reject mean-variance spanning of the equally-weighted index of fund returns for the six countries. Using the FT.Actuarias benchmark with the Investable Composite-mimicking portfolio
} 
If the discount factor $m_{t+1}^{T}$ correctly prices all traded assets in the U.K. and the U.S., all returns available to U.S. and I.K. investors should satisfy equation (1). That is, viewing the returns as payoffs, their prices should be one. Our integration measure arises from using the definition for covariance to rewrite equation (3) and solving for the expected return ${ }^{21}$ :

$$
E\left[R_{t+1}\right]=\frac{1}{\alpha^{T}}-\imath-\frac{\operatorname{Cov}\left(m_{t+1}^{T}, R_{t+1}\right)}{\alpha^{T}} .
$$

When returns covary positively with the discount factor, expected returns are lower. We first compute the expected return for country fund returns, $E\left[R_{t+1}^{P}\right]$. Although our pricing kernel does not price NAV-returns, we also use (11) to compute the expected return for net asset values, $E\left[R_{t+1}^{N}\right]$. We denote the difference by $\Delta \equiv E\left[R_{t+1}^{P}\right]-E\left[R_{t+1}^{N}\right]$.

We expect $\Delta$ to be positive when investment restrictions are binding. If the market was fully open, net asset values and country fund returns would be priced similarly, and the difference in expected returns would be small. If investment restrictions are effectively binding and investors cannot freely access the local market except through the country fund, price segmentation arises and investors "give up" part of the diversification bencfits of emerging market exposure. The statistic $\Delta$ measures the reduction in expected return investors are willing to "pay" to receive the original exposure.

The measure is not perfect for several reasons. First, identifying $m_{t+1}^{T}$ as a function of benchmark returns is difficult. For cxample, when an emerging market is opened up through a country fund and its stock returns are not spanned by world assets, the investment opportunity set of world investors changes and so will their pricing kernels. Second, the measure is potentially affected by factors such as local market inefficiencies, foreign exchange risk, and political risk, that may affect the local and global pricing of the underlying assets so that investment barriers have to be interpreted very broadly. In fact, our framework of stochastic discount factors which price returns in equation (1) is strictly valid only in complete. frictionless markets (see, for example, Hansen and Jagannathan [1991] and Luttmer [1991]). Third, the measure is affected by the extent of diversification benefits the underlying assets offer. For example, it is conccivable that a fully segmented market only trades stocks that have perfectly correlated cash flows with companies in developed countries. In this case. $I$ will probably be low or negative. despite the market being fully segmented. Implicitly. we

provides similar results.

${ }^{21}$ Cochrane [1994] provides a thormagh development 
assume that local emerging market returns are not spanned by developed market returns. Of course, this is exactly the claim made by DeSantis [1993] and Harvey [1994]. In what follows we also show that net asset value returns for our six countries are not spanned by the benchmarks we used in Section 3.

\subsubsection{Empirical Results}

We begin by reporting simple mean-variance spanning tests for the six countries of interest. using the country fund benchmarks from Section 3. Table 6, Panel 1 reports tests for both net asset value (NAV) returns and country fund returns. For the NAV and the country fund returns, we form a value-weighted index of funds targeting each country. Therefore, each test has two degrees of freedom. Note first that only the net asset value returns for Turicy are spanned (marginally) by the benchmark. When the test employs the NAV returns for the individual Turkish funds rather than an index, we reject spanning at the $5 \%$ but not at the $1 \%$ level. Hence, the returns in the six countries do offer diversification bencfits. conditional on their markets being open. More surprisingly, for five of the six countries. the country fund price returns do not offer diversification benefits. ${ }^{22}$ The exception is the value-weighted portfolio of Korea funds. When individual funds are used, the Turkish and Thai funds also offer diversification benefits. Hence, for three countries, the differential pricing between country funds and the underlying assets has led to the disappearance of all diversification benefits. In our pricing framework, it is natural to expect some reduction in the diversification benefits of funds relative to net asset values because of time-variation in the stochastic discount factor. $m_{i+1}^{T}$, which is common to all funds. It is not clear why they should completely disappear for some countries but remain for others, although this may depend on the nature of investment restrictions.

We also report the weights on a mimicking portfolio of the benchmark assets for the price returns. As above, these weights are computed by exploiting the fact that when meanvariance spanning holds, the test returns can be written as a linear function of the benchmark returns with the coefficients surnming to one (see also Appendix A). The mimicking portfolio for fund returns place large weights on mature market closed-end funds. ${ }^{23}$

Results on expected returns and the market integration measure, $\Delta$, are reported in Table.

\footnotetext{
${ }^{22}$ These results are similar using the FT-Actuaries benchmark.

${ }^{23}$ For the FT-Actuaries benchmatk, the Pacific Index receives a large weight for Thailand, Taiwan and Turkey.
} 
6, Panel 2 for each country. We identify $m_{t+1}^{T}$ as the discount factor which prices the six value-weighted indices of fund returns, using the closed-end fund benchmark described in Section 4.1 (recall equation (10) and the ensuing discussion). We also computed the market integration measure for each country using the $m_{t+1}^{T}$ that prices the six IFC Investablemimicking fund portfolios, and the results are very similar. The $\Delta$ measure is computed for value-weighted indices of fund returns targeting each country.

The segmentation measure $\Delta$ is relatively high (greater than $5 \%$ ) for three countries (Indonesia, Thailand, and Taiwan), and low or negative for the three remaining countries in the analysis (Korea, Philippines and Turkey). As an aid in interpreting the results. Table 7 lists some characteristics of the six stock markets. Table 7 illustrates the difficulty in gauging the degree of market integration from general market characteristics and the regulatory framework of different countries. For example, Korea, Taiwan and Thailand are relatively large, liquid markets with low political risk, stable exchange rate policies and numerous possibilities for indirect access by foreigners using country funds and American Depositary Receipts (ADRs). However, there are foreign ownership restrictions in all three countries. Thailand maintains two separate listings for common stocks which have reached foreign ownership limits, one for locals (the "Main Board") and one for foreigners (the "Alien Board"). Prices on the Alien Board are typically higher than prices on the Main Board (ser Bailey and Jagtiani (1994]). Our finding of $\Delta=5.75 \%$ for Thailand confirms the findings in Bailey and Jagtiani who document the effectiveness of foreign ownership restrictions in the Thai capital markets.

Taiwan also has strict limits on foreign ownership. In January 1991, Qualified Foreign Institutional Investors (QFIIs) were allowed to invest directly in Taiwan's stock market. In the aggregate, foreign investment in each of the listed companies is limited to $10 \%$ of the shares outstanding. and QFIIs ran buy no more than $5 \%$ of the shares. In addition, there is a ceiling on total foreign invest ment which was recently raised to $\$ 10$ billion (in March 1993). The value of $6.60 \%$ for $\Delta$ confirms the effectiveness of these restrictions. The surprising result is for Korca, wherc $\Delta$ is only $1.41 \%$. Regulations on foreign participation prohibited direct access to the Korean market until January 1992. Foreign ownership is limited to $10 \%$ in so-called unlimited industries and $8 \%$ in limited industries (which includes communications and defense). Recently the $10 \%$ coiling was raised to $25 \%$ for 45 firms which hit the $10 \%$ cap. However, the low number may reflect the many country funds available to investors. Bekaert and Harvey [199.1] also find that the Korean market appears to be integrated wijth 
global capital markets. The faci that both Korea and Taiwan underwent capital market liberalizations during the sample may affect the results and we address this issue in Section 4.2 .

From Table 7 . Indonesia the Philippines and Turkey appear less developed, less liquid. and more prone to political and currency risk than the preceding three markets. In addition. they have fewer country funds and ADR programs. On the other hand, none of these countries appears to have binding foreign ownership restrictions. Our segmentation measure implies that Indonesia is the most segmented of the six markets. It is also the only country for which $\mathcal{J}$ is significantly different from zero. Since 1988, foreigners have been able to buy up to $49 \%$ of shares in listed companies. However, certain blue chip shares frequently reach that limit and foreign investors are forced to pay a premium for these shares. Investors are only willing to forego about $1 \%$ in expected return to obtain barriers-free exposure to Turkey. For the Philippines, $\Delta$ is actually negative. The results for Turkey and the Philippines may reflect the fact that these markets are effectively integrated with global markets ${ }^{24}$, or it could reflect idiosyncratic features of the funds. As an example of the latter, Diwan et al. [1993] find that the U.S.traded Turkish Investment Fund (TKF) held a large share of its portfolio in U.S. Treasury bills early after inception, a period included in our sample.

\subsection{Investment Liberalizations and Mean-Variance Spanning}

It has sometimes been argued that the movement toward market integration will reduce the diversification benefits of emerging markets. While our sample is too short to allow a fully. dynamic analysis, for four heavily restricted markets a significant investment liberalization takes place in the middle of the test period. An investment liberalization can be viewed as a move toward market integration. Closed-end country funds often receive special rights in invest in closed markets before restrictions are lifted for other foreign investors, so we might expect that the test assets are not spanned by the benchmark before but they may be after the liberalization. To test this conjecture, we modify the specification of the discount factor

\footnotetext{
${ }^{24}$ Although foreign investors wer" given complete access to shares in the Philippines with the Foreign Investment Act of November 1991. some companies have subsequently been given foreign ownetship limits. The restricted shares now trade at substantial premiums to local shares.
} 
as follows. Recall that

$$
m_{t+1}^{\alpha_{1}}=\alpha_{i}+\beta_{1 i}\left(R_{t+1}^{1}-E\left[R_{t+1}^{1}\right]\right)+\beta_{2 i}\left(R_{t+1}^{2}-E\left[R_{t+1}^{2}\right]\right)
$$

for $i=1,2$, where $\alpha_{i}$ is prespecificd and does not affect the test statistic for mean-variance spanning. Instead of testing the hypothesis $\beta_{2 i}=0(i=1,2)$, we redefine $\beta_{2 i} \equiv \widetilde{\beta_{2 i}} D_{t+1}$, where $D_{t+1}$ is equal to 1 beforc the liberalization and 0 afterwards. If the hypothesis $\widetilde{\beta_{2 i}}=0$ $(i=1,2)$ cannot be rejected, the benchmark spans the test assets before and after the liberalization. On the other hand, if $\widetilde{\beta_{2 i}} \neq 0(i=1,2)$, then the test assets are spanned by the benchmark assets after the liberalization but not before.

The results for the invest ment liberalizations are contained in Table 8 . The table considers funds investing in four countries: Brazil, India, Korea and Taiwan. In the first column, the table reports a Wald statistic for the test that $\widetilde{\beta_{2 i}}=0(i=1,2)$, estimated from the GMM system. In all four cases we cannot reject the hypothesis that $\widetilde{\beta_{2 i}}=0(i=1,2)$ at the five percent level. Failure to reject this hypothesis is not surprising since in general the $\beta$ coefficients in the discount factor are not estimated precisely.

Table 6 also reports results from mean-variance spanning tests before and after the liberalization. If the investment restriction was a binding constraint before the liberalization. we would expect to reject spanning before but not afterwards. In fact, we are unable to reject spanning before or after the change for two of the four countries we consider. We are able to reject the liberalization hypothesis for Tajwan: the Taiwan funds are not spannerl before but are spanned after the liberalization. For Korea, however, we reject spanning after the liberalization but not before. In sum. examining specific investment liberalizations for heavily restricted markets reveals that only the opening of Taiwan's market had a significant negative impact on the diversification benefits from holding closed-end funds.

\section{Conclusion}

The fanfare surrounding emerging equity markets continues to attract international investors. Most studies that address the portfolio benefits from emerging markets gloss over the tran:action costs and other barriers to investment associated with these markets. In the precent study we examine the diversification benefits from holding closed-end country funds whirl invest in emerging markets, and compare them to the diversification benefits associatcd with 
the IFC Investable indices. Emerging market closed-end funds represent exposure to emerging markets that is actually attainable by foreign investors at relatively low cost, while the IFC Investables arc at tainable in theory but ignore all effective investment costs or restric. tions with the exception of foreign ownership restrictions.

We find that U.K. epmerging market funds provide statistically significant diversification gains in unconditional tests, while comparable U.S. funds do not. The IFC Investable indices corresponding to the funds in our sample yield unequivocal diversification benefits. A Monte Carlo experiment demonstrates that our tests have fairly low power against one interesting alternative for large GMM systems, but the power is about $70 \%$ for smaller systems. Ncrertheless, the performance result is robust to a number of extensions, and appears to derive from differences in portfolio selection by fund managers. Using lagged fund premiums is conditioning information produces significant gains for both U.S. and U.K. funds.

Our analysis of price segmentation and diversification benefits suggests that the differential pricing of fund shares and $\mathrm{NAV}$ s has contributed to the disappearance of diversification benefits for half of the countries we examine. Despite the existence of substantial premiums on Korean funds, they continue to provide strongly significant benefits. We propose a measure of market segmentation which captures the notion that investors may be willing to forego expected return for direct access to a fund's NAV instead of the fund's shares. The measure suggests that barriers to investment, broadly interpreted, are especially effective in Indonesia, Taiwan, and Thailand, but not in Korea, Turkey and the Philippines. Finally, tlic opening of Taiwan's stock market to foreign investment in January, 1991, had a significant. negative impact on the diversification benefits from holding its country funds.

The power and small sample properties of our mean-variance spanning tests descrw. further study. In particular, the mean-variance spanning hypothesis is closely related io the mean-variance efficiency hypothesis used in tests of single or multifactor asset pricing models. Our results suggest that tests using large GMM systems may have considerable sizc distortions and poor power properties. 


\section{References}

[1] Ammer, J., 1990, "Expenses, Yields, and Excess Returns: New Evidence on Closed End Funds Discounts from the ITK," LSE Financial Markets Discussion Paper No. 108.

[2] Andrews, D.W.K., 1991, "Heteroscedasticity and Autocorrelation Consistent Covariance Matrix Estimation," Fconometrica 59, 817-858.

[3] Bailey, W. and J. Lim, 1992, "Evaluating the Diversification Benefits of the New Country Funds," Journal of Portfolio Management, Spring 1992, 74-80.

[4] Bailey, W. and J. Jagtiani, 1994, "Foreign Ownership Restrictions and Stock Prices in the Thai Capital Market.” Journal of Financial Economics 36, 57-87.

[5] Bansal, R., Hsieh, D. and S. Viswanathan, 1993, "A New Approach to International Arbitrage Pricing," Journal of Finance 48, 1719-1747.

[6] Bekaert. G., 1994. "Market Integration and Investment Barriers in Emerging Equity. Markets," The World Bank Economic Retiew, forthcoming.

[7] Bekaert, G. and C. Harvey, 1994, "Time-Varying World Market Integration," working paper, Graduate School of Business, Stanford University.

[8] Bekaert, G., Garcia, M. and Harvey, C., 1994, "The Role of Capital Markets in Economic Growth," working paper, Graduate School of Business, Stanford University.

[9] Bekaert, G. and M.S. Urias. 1994a. "The Closed-End Fund Puzzle Revisited: Evidenor from U.K. Investment Trusts and Offshore Funds," rescarch notes, Graduate School of Business. St anford University:

[10] Bekaert. G. and M.S. Virias. 1994b, "Emerging Market Diversification Using Countr! Funds," research notes. Giraduate School of Business, Stanford University.

[11] Bodurtha, J.N., Kim, I)., and C.M.C. Lee, 1993, "Closed-End Country Funds and I..S. Market Sentiment," working paper, University of Michigan.

[12] Bollerslev, Г., 1990, -Modeling the Coherence in Short Run Nominal Exchange Rates. A Multivariate Generalized ARCH Model," Revieu of Economics and Statistics i2. 498-505. 
[13] Bonser-Neal, C., Brauer, G., Neal, R., and S. Wheatley, 1990, "International Investment Restrictions and Closed-End Country Fund Prices," Journal of Finance 45, 523-548.

[14] Brauer, G., 1988, "Closed-Fnd Fund Shares' Abnormal Returns and the Information Content of Discounts and Premiums," Journal of Finance 43, 113-127.

[15] Chang, E., Eun, C., and R. Kodolny, 1993, "International Diversification Through Closed-End Country Funds:" working paper, College of Business and Management. University of Maryland.

[16] Chen, Z. and P. Knez, 1994, "Measurement of Market Integration and Arbitrage." working paper. Graduate School of Business, University of Wisconsin-Madison.

[17] Cochrane, J.H., 199:, "Discrete Time Empirical Finance," manuscript, Graduate Sclsool of Business, University of Chicago.

[18] DeSantis, G., 1992. "Volatility Bounds for Stochastic Discount Factors: Tests and Implications from International Stock Returns," working paper, University of Southem California.

[19] DeSantis. G.. 1993. “Asse: Pricing and Portfolio Diversification: Evidence from Emerging Financial Markets," Symposiun on Portfolio Investment in Developing Countries. World Bank.

[20] Divecha, A.B., Drach. I. and D. Stefek, 1992, "Emerging Markets: A Quantitatiur Perspective," Journal of Portfolio Management, Fall 1992, $41-50$.

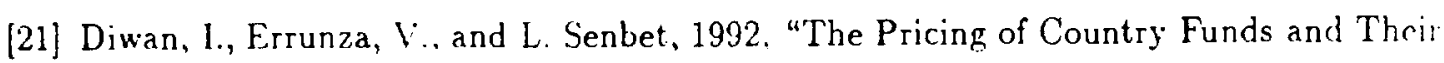
Role in Capital Mobilization for Emerging Economies." working paper No. 1058, World Bank.

[22] Diwan, I., Errunza, Y.. and I.. Senbet, 1993, "National Index Funds - Empirical Perspectives," working paper. World Bank.

[23] Dumas, B. and B. Solnit. 1993, "The World Price of Foreign Exchange Risk:" working paper, H.F.C. School of Management

[24] Errunza, V. and E. Losy. 1985. "International Assef Pricing Vnder Mild Segmentation: Theory and Test," Journal of Finance 40, 105-123. 
[25] Eun, C.S. Janakiramanan, S., and L.W' Senbel, 1994, "The Design And Pricing of Country Funds Under Market Segmentation," working paper, College of Business and Management, University of Maryland.

[26] Ferson, W.E., 1993, "Theory and Empirıcal Testing of Asset Pricing Models," forthcoming in: Jarrow, R.A.. Ziemba, W.T. and V. Maksimovic, The Finance Handbonk (North-Holland, Amsterdanı).

[27] Ferson, W.E. and S. Foerster, 1994, "Finite Sample Properties of the Generalized Method of Moments in Tests of Conditional Asset Pricing Models," Journal of Financinal Economics 36, 29-55.

[28] Ferson. W.E., Foerster. S. and D.B. Keim, 1993, "General Tests of Latent Variables and Mean-Variance Spanining." Journal of Finance 48, 131-156.

[29] Gallant, R. and G. Tauchien, 1992, "Semi-Nonparametric Estimation of Conditionally: Heterogeneous Processes: Asset Pricing Implications," Econometrica 57, 1091-1120.

[30] Hansen, L.P., 1982, "Large Sample Properties of Generalized Method of Moments Estimators," Econometrica 50, 1269-1286.

[31] Hansen, L.P. and R. lagannathan, 1991 "Implications of Security Market lata for Models of Dynamic Econonies," Journal of Political Economy 99, 225-262.

[32] Hansen. L.P. and S.F. Richard, 1987, "I he Role of Conditioning Information in Deducing Testable Restrictione Implicd by Dynamie Asset Pricing Models," Economelrica 5. . $58 i-613$.

[33] Hardouvelis, G. La Porta. R.. and T. Wizman, 1993. "What Moves the Discount on Country Equity Funds?" working paper No. 93-24, Federal Reserve Bank of New lork.

[34] Harvey, C.. 1991, "The World Price of Covariance Risk," Journal of Finance 16. 111 . 157.

[35] Harvey, C., 1993, "Portolio Enhancernent Using Emerging Markets and Conditioniing Information," Symposium on Portfolin Investment in Developing Countries. Horlu Bank. 
[36] Harvey, C., 1994, "Predictable Risk and Returns in Emerging Markets," working paper. Fuqua School of Business. Duke University.

[37] Huberman, G. and S.A. Kandel. 1987, "Mean-Variance Spanning:" Journal of Finance $42,383-388$.

[38] Jobson, J.D. and B. Korkie, 1989, “A Performance Interpretation of Multivariate Tests of Asset Set Intersection, Spanning and Mean-Variance Efficiency, Journal of Financial and Quantilative Analysis 24, 185-204.

[39] Lee, C.M.C., Shleifer, A., and R.H. Thaler, 1991, "Investor Sentiment and the ClosedEnd Fund Puzzle." Journal of Finance 46, 75-110.

[40] Luttmer, E., 1991, "Assct Pricing in Economies with Frictions," working paper, Pniversity of Chicago.

[41] McCloskey, D.N., 1985, "The Loss Function Has Been Mislaid: The Rhetoric of Significance Tests, ${ }^{\top}$ AEA Papers and Proceedings, 201-205.

[42] Newey, W.K. and K.D. West. 1987a, "Hypothesis Testing with Efficient Method of Hornents Estimation." International Economir Revicw 28, $777-787$.

[43] Newey, W.K. and K.D. West, 1987b, "A Simple, Positive Semi-Definite, Heteroscedasticity and Autocorrelation Consistent Covariance Matrix," Econometrica 55, i03-708.

[44] Sharpe, W.F., 1994, ", Journal of Portfolio Management,.

[45] Snow, K., 1991, "Diagnosing Asset Pricing Models Using the Distribution of Asset Returns," Journal of Finnes 46. 955-933.

[46] Stulz. R.M., 1981, "On the. Efferts of Barriers to International Investment." Joumal of Finance 36, 923-9.34.

[47] Thompson. R., 1978. "The Information Content of Discounts and Premiums on Closer. End Fund Shares," Journal of Financial Economics 6, 151-186

(48) Tuckman, J., and Vila 1004. "Holding Costs and Equilibrium Arbitrage." working paper, Massachusetts Instituie of Technology: 
[49] Urias, M., 1992, "Explaining the Time-Variation in Closed-End Country Fund Returns." working paper, Graduate School of Business, Stanford University.

[50] Wheatley, S., 1988, "Some Tests of International Equity Integration," Journal of Financial Economics 21, 177.212. 
</ref_section> 
Table 1

Emerging Market Funds: Total Net Assets

\begin{tabular}{|c|c|c|c|}
\hline Country or Region & Closed-End & Open-End & Total \\
\hline \multicolumn{4}{|c|}{ End 1891} \\
\hline Southeast Asia & 10367.5 & 7886.3 & 18253.8 \\
\hline Latin America & 3272.3 & 367.4 & 3639.7 \\
\hline Global & 2730.4 & 85.7 & 2816.1 \\
\hline Other & 3234.0 & 1.2 & 3235.2 \\
\hline Total & 15815.1 & 7129.0 & 22944.1 \\
\hline \multicolumn{4}{|c|}{ End 1893} \\
\hline Southeast Asia & 12340.8 & 34121.7 & 46462.5 \\
\hline Latin America & 5569.4 & 9266.4 & 14835.8 \\
\hline Global & 3379.7 & 18271.2 & 276.50 .9 \\
\hline Other & 3655.2 & 1496.0 & 5151.2 \\
\hline Total & 30945.1 & 63155.3 & 94100.4 \\
\hline
\end{tabular}

Notes:

Figures are in millions of $\mathrm{US}$. dollars. There is no overlap between country and regional totals. Includes all funds worldwide that invest in equity or fixed-income markets. Less than 20 prrcent of total fund assets in 1993 are fixed-income. with the majority of those invested in Latin American insucs. There is a group of funds which invests in emerging Asia and Japan, with total assets of about $\$ 21$ billion in 1993 , that is excluded from the totals. Source is Lipper Emerging Markets Fund Service 
Table 2

Country Fund Sample General Characteristics:

January 1986-A ugust 1993

\begin{tabular}{|c|c|c|c|c|c|c|c|}
\hline Fund & Symbol & Start & Asoet6 & Premium & $\%\left(r_{i}^{P}\right)$ & VR1 & VR2 \\
\hline \multicolumn{8}{|c|}{ Pnnel 1: U.S. Emerging Market Funds } \\
\hline Argentina & AF & 911021 & 55.9 & 12.833 & 4.780 & 1.121 & 0.308 \\
\hline Asia Pacific & APB & 870424 & 184.1 & -4.426 & 5.554 & 0.774 & 0.414 \\
\hline Brazil & $\mathrm{B} 7 \mathrm{~F}$ & 880331 & 191.4 & -11.143 & 6.193 & 1.532 & 1.806 \\
\hline Chile & $\mathrm{CH}$ & 890926 & 165.0 & -5.455 & 5.470 & 0.822 & 0.268 \\
\hline Templeton E.M & ENT & 870226 & 192.5 & 3.775 & 4.961 & 0.782 & 0.270 \\
\hline Firat Philippine & $F \Gamma F$ & 891108 & 137.8 & -17.282 & 4.407 & 0.803 & 0.15 .5 \\
\hline Indonesia & IF & 90301 & 10.3 & 7.563 & 5.609 & 0.886 & 0.152 \\
\hline India Growth & JaF & $880 \times 12$ & 58.2 & -3.634 & 5.447 & 1.180 & 0.584 \\
\hline Jakarta Grometh & ICF & 900110 & 35.6 & 1.712 & 5.290 & 0.943 & 0.157 \\
\hline horm & KF & 850102 & 254.7 & 54.816 & 6.109 & 0.916 & 0.247 \\
\hline Latin Am. Invt & LAM & 900725 & 73.9 & -6.233 & 5.178 & 1.049 & 0.314 \\
\hline Latin Am. Fquity & $\mathrm{I} . \mathrm{AQ}$ & 911022 & 83.9 & -5.773 & 3.956 & 0.967 & 0.437 \\
\hline Fmerging Mexico & $M F F$ & 901002 & 103.9 & -8.153 & 5.395 & 0.654 & 0.345 \\
\hline Malaysin & MF & 870508 & 131.2 & -2.185 & 6.785 & 0.833 & 0.210 \\
\hline Morgan Slantey EM & $M S I$ & 911025 & 184.4 & 4.998 & 2.998 & 1.099 & $0.2 \div 3$ \\
\hline Mexien & $M \lambda F$ & 810608 & 697.7 & -17.154 & 7.074 & 0.767 & 0.553 \\
\hline Portukal & $\operatorname{PST}$ & 891101 & 51.1 & .5 .278 & 5.352 & 0.866 & $0.18 i$ \\
\hline ROC Tajwan & $\mathrm{ACC}$ & 890512 & 251.1 & -1.714 & 5.585 & 0.759 & 0.451 \\
\hline Scudder New Asia & SAP & 870618 & 123.1 & -10.701 & 4.841 & 0.808 & 0.423 \\
\hline Thai Capital & $\Gamma C$ & 900523 & 75.6 & -7.992 & 4.954 & 0.866 & 0.508 \\
\hline Thai & THF & 880217 & 210.4 & 14.310 & 5.578 & 0.940 & 0.400 \\
\hline Turkish Luvest ment & TKF & 891215 & 50.0 & 1.335 & 5.895 & 1.208 & 1.145 \\
\hline Taiman & TWN & 861216 & 161.7 & 26.897 & 6.992 & 1.534 & 0.915 \\
\hline \multicolumn{8}{|c|}{ Panel 2: U.K. Emerging Market Trunts } \\
\hline Abtruat New Thai & AETHAI & 891222 & 28.2 & -18.876 & 5.259 & 0.612 & 0.745 \\
\hline Abtrust New Dawn ${ }^{\dagger}$ & ARIST & 890512 & 59.0 & -12.315 & 3.963 & 0.799 & 0.622 \\
\hline Bets Global EAl' & BGEMI & 900306 & 62.8 & .9 .961 & 2.962 & 1.296 & 0.832 \\
\hline Brazil* & BRAIT & 920554 & 65.9 & -11.643 & 4.881 & 0.762 & 0.730 \\
\hline Drayton Korea & [ifki & 911205 & 43.0 & -13.358 & 3,745 & 0.897 & 0.948 \\
\hline EFMI Dragon ${ }^{\dagger}$ & EFMlik & 880311 & 240.1 & .9 .243 & 5.702 & 0.986 & 0.306 \\
\hline Fleming EM: & FEMIK & 910726 & 120.8 & -2.925 & 2.473 & 1.328 & 0.900 \\
\hline First Philippine' & $F P \cdot$ & 891215 & 51.8 & -30.048 & 4.635 & 1.330 & 1.0 .30 \\
\hline Gartmere Pacific: & GES & 000119 & $1: 2.9$ & .14 .665 & 3.822 & 0.850 & $0.65 i$ \\
\hline EFM Java & JAVA & 9005 is & 13.7 & -5.361 & 4.211 & 1.328 & 0.624 \\
\hline Kores Liberalisstion & $K L F$ & 300615 & 34.5 & -20.012 & $5.7 ! 0$ & 1.424 & 0.679 \\
\hline Koren Eusnpe" & KORFIR & 890623 & 153.8 & 24.98 .5 & 5.941 & 0.788 & 0.348 \\
\hline Latin America" & LATIT & $90070) ?$ & 153.8 & -6.227 & 5.207 & 1.149 & 0.555 \\
\hline Pacific Horizon* & PHIT & 897829 & 25.1 & -14.816 & 4.404 & 1.081 & 0.411 \\
\hline Schroder Korea" & SCHRKT & 911213 & 47.1 & -2.818 & 5.600 & 0.718 & 0.391 \\
\hline Siam Select & SIAM & 900406 & 43.9 & -7.948 & 2718 & 2.124 & 1.8 .31 \\
\hline Thomton Asian' & TAFAI!'i & 890728 & 164.2 & -11.809 & 3.740 & 0.927 & 0.759 \\
\hline Templ-ton F.Af & TMPIT: & 890929 & 375.0 & -1.097 & .3 .086 & 1.228 & 0.782 \\
\hline Turkey & TIIRK & $900 \times 803$ & 39.8 & -14.566 & 3.050 & $2.55 ?$ & 2.401 \\
\hline
\end{tabular}


Table 2

Country Fund Sample General Characteristics:

January 1986-August 1993

\begin{tabular}{|c|c|c|c|c|c|c|c|}
\hline Fund & Symbol & Start & A soets & Premium & $\% \sigma\left(r_{i}^{P}\right)$ & VR1 & $\mathbf{V R 2}$ \\
\hline \multicolumn{8}{|c|}{ Panel 3: U.S. Mature Market Funds } \\
\hline Europe & EF & 900427 & 93.2 & -7.411 & 3.783 & 1.032 & 0.269 \\
\hline France Growth & FRF & 900511 & 183.5 & -13.328 & 4.415 & 0.923 & 0.256 \\
\hline Emerging Germany & FRG & 900329 & 114.6 & -12.504 & 4.502 & 0.954 & 0.416 \\
\hline Germany & GER & 860718 & 142.6 & 3.805 & 5.933 & 0.912 & 0.200 \\
\hline New Germany & GF & 900125 & 331.2 & -13.272 & 4.712 & 1.004 & 0.480 \\
\hline Growth Fd Spain & GSP & 900215 & 172.3 & -13.602 & 3.684 & 0.721 & 0.461 \\
\hline First Australia & IAF & 860102 & 98.2 & -12.687 & 4.819 & 1.310 & 0.605 \\
\hline First Theris & IBF & 880419 & 51.4 & -4.926 & 5.302 & 0.929 & 0.220 \\
\hline lrish Investment & IRL & 900330 & 45.4 & -17.186 & 3.496 & 1.090 & 0.441 \\
\hline It aly & ITA & 860226 & 58.0 & -9.906 & 5.205 & 0.932 & 0.297 \\
\hline Japan OTC & JOF & 900314 & 79.0 & 6.267 & 5.376 & 1.016 & 0.597 \\
\hline Austris & CST & 830922 & 64.8 & -4.985 & 6.320 & 1.062 & 0.399 \\
\hline Singapore & SGF & 900725 & 66.3 & .7 .599 & 4.0 .58 & 0.932 & 0.205 \\
\hline Spain & SNF & 880621 & 90.0 & 13.093 & 6.066 & 0.970 & 0.339 \\
\hline Swisu Helvetia & sWZ & 870819 & 160.1 & -5.202 & 3.945 & 0.911 & 0.331 \\
\hline United Kingdom & UK & 870807 & 45.0 & -14.047 & 4.470 & 0.811 & 0.392 \\
\hline \multicolumn{8}{|c|}{ Panel 4: U.K. Mature Market Truats } \\
\hline Fleming American ${ }^{\prime}$ & FAMN & 870206 & 378.2 & -14.978 & 3.469 & 0.603 & 0.598 \\
\hline F \& C Eurotnust ${ }^{\dagger}$ & FCEl' & 870102 & 191.4 & -2.730 & 3.249 & 0.717 & 0.522 \\
\hline Fleming Far East ${ }^{\dagger}$ & FFFT & 870102 & 811.2 & -17.096 & 3.792 & 0.556 & 0.502 \\
\hline First Ereland & FIC & 900316 & NA & -17.825 & 2.867 & 1.389 & 1.193 \\
\hline Fleming Japanarel & FL, JA & 870206 & 426.8 & -13.317 & 4.002 & 0.615 & 0.579 \\
\hline First Spanish & FSPAN & 880805 & 40.8 & -10.740 & 3.508 & 0.799 & 0.670 \\
\hline German ${ }^{t}$ & GRMIT & 900302 & 54.9 & -14.734 & 3.332 & 0.792 & 0.582 \\
\hline German Smaller Cos." & GRMS & 870102 & 62.8 & -18.375 & 3.044 & 0.888 & 0.727 \\
\hline GT Japan' & GTJA & B70102 & 222.8 & -12.332 & 3.996 & 0.666 & 0.645 \\
\hline Govett Oriental' & LVIT & 870102 & 855.2 & -16.834 & 3.953 & 0.563 & 0.661 \\
\hline Paribas French" & PRBS & 870515 & 58.1 & -9.845 & 3.332 & 0.784 & 0.197 \\
\hline TR Pacific! & TRIPI & 871127 & 152.2 & -7.963 & 4.194 & 0.887 & 0.535 \\
\hline \multicolumn{8}{|c|}{ Panel 3: U.S. Domestic Market Funds } \\
\hline Adams Express & $A D X$ & 860102 & 8.32 .2 & -7.197 & 2.409 & 0.957 & 0.678 \\
\hline Baker Fentress & BKF & 671127 & 427.3 & -17.127 & 2.433 & 0.753 & 0.453 \\
\hline General Am. Invest. & GAM & 860102 & 514.0 & -11.301 & 3.259 & 0.558 & 0.541 \\
\hline Source Capital & SOR & 260102 & 277.3 & 3.547 & 2.052 & 0.828 & 0.420 \\
\hline Tricontinental Corp. & TY & 860102 & 2047.8 & -9.177 & 2.298 & 0.805 & 0.956 \\
\hline \multicolumn{8}{|c|}{ Fanel 6: U.K. Domestic Market Trugts } \\
\hline Allisncel & Al. NCT & 870102 & 1399.6 & -15.952 & 2.195 & 0.431 & 0.857 \\
\hline Edinburgh: & EDIS & 870102 & $16 \div 6.2$ & -17575 & 2.801 & 0.333 & 0.535 \\
\hline Fleming Claverhouse: & Follk & 870102 & 117.5 & -9.220 & 2.949 & 0.543 & 0.829 \\
\hline Foreign A: Colnnialt & FHCl & 870102 & 2168.5 & .14 .444 & 3.057 & 0.439 & 0.521 \\
\hline Scotiah Mortgare: & 5911 & 8.0102 & $1.5 \times 0.5$ & -17.690 & 2.880 & 0.344 & 0.634 \\
\hline TR City of London! & Thith & 870102 & $45 \overline{9} .7$ & .7 .211 & 3.003 & 0.285 & 0.633 \\
\hline Witn' & Wit: & $5: 0102$ & 1404.3 & $-21.3 \times 3$ & 2.75 .5 & 0.369 & 0.8 .83 \\
\hline
\end{tabular}


Notes (Table 2):

All U.S. funds trade on the NYSF. except for IAF and IBF. which trade on the AMIEX. All inveatment trusts trade on the London Stack Exchange. Fund net aaset, are in milliona of 11.S. dollars, computed in April 1993. The source for investment trust assets is the Apociation of Inteotment Trust Companies Monthly Informstion Service. 'NA' indicates not avajlable Other itstistic are computed in the currency in which the fund trades. The investment trusts in the sample are quoled in pence except for BRAIT, KOREUR, LATIT and SCHRKT, which are quoted in dollars.

Start is the date when fund coverage begins. It corresponds to the IPO date for U.S. funds offered after 1985 and for U.K. funds offered arter 1986 .

$P R M_{t}$ is the premium, defined by: $P_{t} \equiv N A V_{t} P R M f_{1}$. Premium is 100 times the average of $\left(P R M_{t}-1\right)$

$\sigma\left(r_{t}^{P}\right)$ is the percentage weekly standard deviation of $\log$ price returns.

The log premium change is then the difference in $\log$ price $\left(r_{i}^{P}\right)$ and $\log N A V\left(r_{i}^{N}\right)$ returns: $\Delta \log \left(P R A_{t}\right)=r_{i}^{P}-r_{i}^{N}$.

VRI is the variance ratio $\sigma^{2}\left(\Delta \log \left(P R A_{1}\right)\right) / \sigma^{2}\left(r_{i}^{P}\right)$, and $V B 2$ is the variance ratio $\sigma^{2}\left(r_{i}^{N}\right) / \sigma^{2}\left(r_{i}^{P}\right)$.

".' indicates inveatment 1 rust for wich diluted NAV is used. A superscript $\dagger$ indicates U.K. funds in our nample that arr included in the FT-Allshare Index of January. 1994. See Section 2 for details. 
Table 3

Unconditional Mean-Variance Spanning Tests

September 1990 - August 1993

\begin{tabular}{|c|c|c|c|c|c|c|}
\hline \multirow[b]{2}{*}{$\begin{array}{l}\text { Benchmark } \\
\text { Assets }\end{array}$} & \multicolumn{6}{|c|}{$\begin{array}{c}\text { Test Assets: p-value } M V_{3} \text { (p-value Empirical Distribution) } \\
\text { [Change in Sharpe Ratio] }\end{array}$} \\
\hline & $\begin{array}{l}\text { U.S. } \\
\text { Funds }\end{array}$ & $\begin{array}{l}\text { U.K. } \\
\text { Funds }\end{array}$ & $\begin{array}{l}\text { U.S. \& U.K. } \\
\text { Funds }\end{array}$ & $\begin{array}{l}\text { U.S. Fund } \\
\text { Index. }\end{array}$ & $\begin{array}{l}\text { U.K Fund } \\
\text { Index }\end{array}$ & $\begin{array}{l}\text { U.S. \& U.K. } \\
\text { Fund Indiers }\end{array}$ \\
\hline U.S., V.K., & 0.6743 & 0.0109 & 0.4178 & 0.1215 & 0.0325 & 0.0213 \\
\hline Europe, & $(0.7910)$ & $(0.0280)$ & & $(0.1280)$ & $(0.0395)$ & $(0.025 .5)$ \\
\hline Pacific & {$[0.1618]$} & {$[0.1294]$} & {$[0.2405]$} & {$[0.0680]$} & {$[0.0564]$} & {$[0.0875]$} \\
\hline U.S. Domestic Index. & 0.6015 & 0.0002 & 0.5382 & 0.1001 & 0.2721 & 0.1032 \\
\hline U.K. Domestic Index. & $(0.7280)$ & $(0.0010)$ & & $(0.1150)$ & $(0.3090)$ & $(0.11 .50)$ \\
\hline $\begin{array}{l}\text { U.S. Mature Market Index, } \\
\text { U.K. Mature Market Index }\end{array}$ & {$[0.1311]$} & {$[0.0958]$} & {$[0.1988]$} & {$[0.0473]$} & {$[0.0246]$} & {$[0.0578]$} \\
\hline
\end{tabular}

\begin{tabular}{|c|c|c|c|c|}
\hline \multicolumn{5}{|c|}{ Panel 2: IFC Investable Indices } \\
\hline $\begin{array}{l}\text { Benchmark } \\
\text { Assets }\end{array}$ & U.S. Investables & U.K. Investables & $\begin{array}{c}\text { U.S Investables } \\
\text { Index }\end{array}$ & $\begin{array}{c}\text { U.K. Investables } \\
\text { Index }\end{array}$ \\
\hline $\begin{array}{l}\text { U.S., U.K.. } \\
\text { Europe, } \\
\text { Pacific } \\
\end{array}$ & $\begin{array}{c}0.0006 \\
{[0.4126]}\end{array}$ & $\begin{array}{c}0.0030 \\
{[0.3051]}\end{array}$ & $\begin{array}{c}0.0007 \\
{[0.0940]}\end{array}$ & $\begin{array}{c}0.0016 \\
{[0.0239]}\end{array}$ \\
\hline $\begin{array}{l}\text { U.S. Domestic Index, } \\
\text { U.K. Domestic Index, } \\
\text { U.S. Mature Market Index, } \\
\text { U.K. Mature Market Index }\end{array}$ & $\begin{array}{c}0.0080 \\
{[0.3732]}\end{array}$ & $\begin{array}{l}0.0014 \\
{[0.2801]}\end{array}$ & $\begin{array}{c}0.0078 \\
{[0.0584]}\end{array}$ & $\begin{array}{c}0.0011 \\
{[0.0117]}\end{array}$ \\
\hline
\end{tabular}

\section{Notes:}

The p-value is the probability value of the chi-square statistic $M V_{3}$. Numbers in parentheses are approximate probability values from the empirical distribution of $M V_{3}$ under the null. See Section 3.2 or the Appendix for details. Numbers in square brackets indicate the approximate change in the Sharpe Ratio from adding the test assets to the benchmark assets

All returns are computed un dwilars, and all indices are equally-weighted. The tests employ 152 weekly obscrations 
Notes (Table 3):

\section{Panel 1}

The U.S. funds included as tests assets are: APB, BZF, CH, EMF, FPF, IF, LAM, MF, MXF, PGF, THF and TKF. The U.K. funds are: ABTHAI, ABTST, EFMDR, FPT, JAVA, LATIT and TURK. These funds make up the fund indices as well. In cases where more than one fund covers a particular country or region, the longer-lived fund was chosen. The same rule applies to the mature market fund benchmarks.

FT-Actuaries World Indices make up the first set of benchmark assets. The Europe index does not include the lnited Kingdom. The serond set of benchmark assets contains indices of closed-end funds.

\section{Pauel 2}

The IFC test assets nert chosen to cover the sarne markets as the corresponding country funds assets. Both indices of IFC Investable returns are equally-weighted. 
Table 4

Country Fund Portfolio Risk Characteristics:

Common U.S. and U.K. Emerging Market Coverage

October 1990-A uguat 1993

\begin{tabular}{|c|c|c|c|c|c|c|c|}
\hline Country/Region & Fund & Domicile & $\alpha$ & $\beta_{L \cdot 1}$ & $\beta_{G . I}$ & $\beta_{I}$ & $\bar{R}^{2}$ \\
\hline \multirow[t]{12}{*}{ Asia-Pacific } & $A P B$ & U.S. & 0.002 & & -0.019 & 0.622 & 0.385 \\
\hline & & & $(0.001)$ & & $(0.068)$ & $(0.055)$ & \\
\hline & EFMDR & U.K. & 0.001 & & -0.126 & 0.626 & 0.354 \\
\hline & & & $(0.001)$ & & $(0.085)$ & $(0.078)$ & \\
\hline & GEP & U.K. & 0.002 & & -0.004 & 0.639 & 0.353 \\
\hline & & & $(0.001)$ & & $(0.074)$ & $(0.073)$ & \\
\hline & PIIT & $U K$ & 0.001 & & 0.129 & 0.5 .59 & 0.252 \\
\hline & & & $(0.001)$ & & $(0.072)$ & $(0.073)$ & \\
\hline & $S A H$ & l:S. & 0.000 & & 0.455 & 0.617 & 0.391 \\
\hline & & & $(0.002)$ & & $(0.166)$ & $(0.097)$ & \\
\hline & TAFAIT & U. K. & 0.000 & & 0.042 & 0.610 & 0.174 \\
\hline & & & $(0.002)$ & & $(0.097)$ & $(0.080)$ & \\
\hline \multirow[t]{8}{*}{ Global } & ABTST & U.K. & 0.002 & & 0.270 & 0.435 & 0.151 \\
\hline & & & $(0.002)$ & & $(0.111)$ & $(0.092)$ & \\
\hline & BCEM & U. $\mathbf{k}$. & 0.001 & & 0.223 & 0.454 & 0.201 \\
\hline & & & $(0.001)$ & & $(0.093)$ & $(0.059)$ & \\
\hline & E.MF & U.S. & 0.004 & & 0.039 & 0.708 & $0.50 ?$ \\
\hline & & & $(0.001)$ & & $(0.059)$ & $(0.047)$ & \\
\hline & TMPLT & U.K. & 0.004 & & -0.026 & 0.388 & 0.092 \\
\hline & & & $(0.002)$ & & $(0.141)$ & $(0.078)$ & \\
\hline \multirow[t]{6}{*}{ Indonesia } & IF & L.S. & -0.001 & 0.331 & 0.009 & 0.454 & 0.586 \\
\hline & & & $(0.001)$ & $(0.131)$ & $(0.172)$ & $(0.030)$ & \\
\hline & JAIA & U.K. & -0.000 & -0.046 & 1.226 & 0.269 & 0.168 \\
\hline & & & $(0.002)$ & $(0.419)$ & $(0.412)$ & $(0.083)$ & \\
\hline & JGF & E.S. & -0.000 & 0.532 & 0.114 & 0.481 & 0.60 .4 \\
\hline & & & $(0.001)$ & $(0.163)$ & $(0.172)$ & $(0.029)$ & \\
\hline \multirow[t]{4}{*}{ Latin America } & $L A M$ & U.S. & 0.003 & & 0.048 & 0.536 & 0.24 .5 \\
\hline & & & $(0.001)$ & & $(0.064)$ & $(0.088)$ & \\
\hline & LATIT & U.K. & .0 .001 & & 0.065 & 0.798 & 0.40 .1 \\
\hline & & & $(0.001)$ & & $(0.050)$ & $(0.076)$ & \\
\hline \multirow[t]{2}{*}{ Philippines } & E P F & $t S$ & 0.003 & -0.003 & 0.408 & 0.241 & 0.417 \\
\hline & & & $(0.001)$ & $(0.058)$ & $(0.115)$ & $(0.040)$ & \\
\hline
\end{tabular}




\section{Table 4}

Country Fund Portfolio Risk Characteristics:

Common U.S. and U.K. Emerging Market Coverage

October 1990-August 1993

\begin{tabular}{|c|c|c|c|c|c|c|c|}
\hline Country/Region & Fund & Domicile & $\alpha$ & $\beta_{L I}$ & $\beta_{G .1}$ & $\beta_{1}$ & $\bar{R}^{2}$ \\
\hline \multirow[t]{2}{*}{ Pbilippines } & FPT & U.K. & 0.002 & 0.162 & 0.895 & 0.414 & 0.330 \\
\hline & & & $(0.003)$ & $(0.184)$ & $(0.318)$ & $(0.089)$ & \\
\hline \multirow[t]{6}{*}{ South Korea } & $\mathrm{KF}$ & U.S. & 0.001 & 0.796 & & 0.439 & 0.595 \\
\hline & & & $(0.001)$ & $(0.111)$ & & $(0.057)$ & \\
\hline & KLF & U.K. & -0.003 & 0.189 & & 0.327 & 0.067 \\
\hline & & & $(0.003)$ & $(0.307)$ & & $(0.152)$ & \\
\hline & KOREUR & U.K. & 0.001 & 0.922 & & 0.476 & 0.463 \\
\hline & & & $(0.002)$ & $(0.143)$ & & $(0.050)$ & \\
\hline \multirow[t]{8}{*}{ Thailand } & АВTHМ & U.K. & 0.000 & 0.331 & 0.552 & 0.755 & 0.609 \\
\hline & & & $(0.002)$ & $(0.173)$ & $(0.362)$ & $(0.043)$ & \\
\hline & SIAM & U.S. & 0.001 & 0.064 & -0.668 & 0.463 & 0.268 \\
\hline & & & $(0.002)$ & $(0.306)$ & $(0.647)$ & $(0.091)$ & \\
\hline & $\mathrm{TC}$ & E.S. & 0.000 & 0.282 & 1.150 & 0.761 & 0.790 \\
\hline & & & $(0.001)$ & $(0.134)$ & $(0.508)$ & $(0.033)$ & \\
\hline & $\mathrm{THF}$ & U.S. & 0.000 & 0.170 & 0.908 & 0.815 & 0.909 \\
\hline & & & $(0.001)$ & $(0.087)$ & $(0.259)$ & $(0.022)$ & \\
\hline \multirow[t]{4}{*}{ Turkey } & TKF & U.S. & 0.002 & 0.523 & 0.138 & 0.799 & 0.800 \\
\hline & & & $(0.002)$ & $(0.125)$ & $(0.360)$ & $(0.035)$ & \\
\hline & TliRh & U. $K$. & 0.003 & -0.026 & 0.719 & 0.258 & 0.109 \\
\hline & & & $(0.003)$ & $(0.125)$ & $(0.375)$ & $(0.080)$ & \\
\hline
\end{tabular}

Notes:

To comparc the risk expowute of fund portfolios, we estimate the following multivariate. linear time series regression using OLS:

$$
r_{1}^{N}=n+\beta_{l \cdot 1} r_{t}^{L \cdot 1}+\beta_{G \cdot 1} r_{t}^{G \cdot l}+\beta_{1} r_{t}^{l}+i_{1}
$$

The dependent variable is the return on $\mathrm{NAV}$ for the fund. $r^{L \cdot 1}$ and $r^{G \cdot 1}$ are the residuals from a linear projection of IFC Local and Global index returns on the Investable Index, and $r^{l}$ is the return on the Investable index. Numbers in parentheses are Newey-West [1987b] standard errors computed using three lags. All returns include dividends and are measured in dollars. Blank spaces indicate that the corresponding index was unavailable or of insufficient length. The South Korean Investable index is available only late in the 
sample, so $r^{L I}$ is replaced with $r^{L G}$ and $r^{I}$ with $r^{G} \cdot \bar{R}^{2}$ is the $R^{2}$ adjusted for degrees of freedom. 
Table 5

\section{Conditional Mean-Variance Spanning Tests}

September 1990 - August 1993

\begin{tabular}{|c|c|c|c|}
\hline \multirow[b]{2}{*}{ Benchmark Assets } & \multicolumn{3}{|c|}{$\begin{array}{l}\text { Test Assets: p-value } M V_{3} \\
\text { [Change in Sharpe Ratio ] }\end{array}$} \\
\hline & $\begin{array}{l}\text { U.S. Fund } \\
\text { Index }\end{array}$ & $\begin{array}{l}\text { U.K. Fund } \\
\text { Index }\end{array}$ & $\begin{array}{l}\text { U.S \& U.K. } \\
\text { Fund Indices }\end{array}$ \\
\hline $\begin{array}{l}\text { U.S. Domestic Index, } \\
\text { U.K. Domestic Index, } \\
\text { U.S. Mature Market Index, } \\
\text { U.K. Mature Market Index }\end{array}$ & $\begin{array}{c}0.0000 \\
{[0.0380]}\end{array}$ & $\begin{array}{c}0.0000 \\
{[0.0270]}\end{array}$ & $\begin{array}{c}0.0002 \\
{[0.0514]}\end{array}$ \\
\hline
\end{tabular}

Notes:

Each country fund index in the benchmark and test assets was scaled by a vector of ones and an index of its own lagged premium changes (the difference between price and NAV returns), doubling the degrees of freedom in the test to $\mathbf{4} \mathbf{n}_{2}$.

The $p$-value is the probability value of the chi-square statistic $M V_{3}$. See Section 3.2 or the Appendix for details. Numbers in square brackets indicate the approximate change in the Sharpe Ratio from adding the test assets to the benchmark assets.

All returns are computed in dollars, and the indices are equally-weighted. The tests employ 152 weekly observations 
Table 6

Market Integration

\begin{tabular}{|c|c|c|c|c|c|c|}
\hline \multicolumn{7}{|c|}{ Pancl 1: Mean-Variance Spanning } \\
\hline & Indonesia & Korea & Philippines & Taiwan & Thailand & Turkey' \\
\hline Return & \multicolumn{6}{|c|}{$p$-value $M V_{3}$ [ Change in Sharpe Ratio ] } \\
\hline \multirow[t]{2}{*}{ Price } & 0.9847 & 0.0078 & 0.1141 & 0.9224 & 0.8877 & 0.4441 \\
\hline & {$[0.0000]$} & {$[0.0014]$} & {$[0.0409]$} & {$[0.0003]$} & {$[0.0034]$} & {$[0.0014]$} \\
\hline \multirow[t]{2}{*}{ NAY } & 0.0000 & 0.0045 & 0.0004 & 0.0100 & 0.0070 & 0.0724 \\
\hline & {$[0.0056]$} & {$[0.0003]$} & {$[0.0331]$} & {$[0.0000]$} & {$[0.0141]$} & {$[0.0031]$} \\
\hline Benchmark & \multicolumn{6}{|c|}{ Weights for Price Returns } \\
\hline U.S. Domestic Index & 0.3973 & 0.2912 & 0.3755 & 0.2623 & 0.4625 & -0.0530 \\
\hline U.K. Domestic Index & 0.0196 & 0.1539 & 0.1857 & -0.1821 & -0.7293 & -0.2784 \\
\hline U.S. Mature Market Index & 0.2529 & 0.3660 & 0.1887 & 0.4840 & 0.4779 & 0.7119 \\
\hline U.K. Mature Market Index & 0.3302 & 0.1888 & 0.2501 & 0.4357 & 0.7888 & 0.6195 \\
\hline \multicolumn{7}{|c|}{ Panel 2: Cost of Barriers to Investment } \\
\hline & Indonesia & Korea & Philippines & Taikan & Thailand & Turkey \\
\hline & \multicolumn{6}{|c|}{ (Standard Error) } \\
\hline$E\left[R_{t+1}^{P}\right]$ & 18.3935 & 11.8572 & 12.0525 & 19.9329 & 15.9425 & 11.8455 \\
\hline & $(84080)$ & $(7.8532)$ & $(7.7457)$ & $(10.2335)$ & $(9.5493)$ & $(10.3070)$ \\
\hline$E\left[R_{i+1}^{N}\right]$ & 10870 & 10.4492 & 13.0712 & 13.3198 & 10.1680 & 10.7808 \\
\hline & $(2.9520)$ & $(5.5802)$ & $(4.5110)$ & $(5.2301)$ & $(6.9726)$ & $(8.1578)$ \\
\hline$\Delta$ & 17.3065 & 1.4080 & -1.0187 & 6.6131 & 5.7745 & 1.0646 \\
\hline & $(7.3065)$ & $(5.6596)$ & $(5.3308)$ & $(8.0604)$ & $(5.3666)$ & $(7.9335)$ \\
\hline $\operatorname{Mean}\left(R_{i+1}^{P}\right)$ & 18.4450 & 14.7772 & 37.3945 & 21.7580 & 22.7877 & 9.1692 \\
\hline $\operatorname{Mean}\left(R_{i+1}^{V}\right)$ & -1.9817 & 5.8931 & 23.7340 & 10.2454 & 21.0070 & 0.6024 \\
\hline
\end{tabular}

Notes:

\section{Panel 1}

The p-value is the probability value of the chi-square statistic $M l_{3}$. See Section 3.2 or the Appendix for details

The test assets are a value-weighted price or value-weighted $N A V$ index return, and the control benchmark is used. Numbers in square brackets indicate the approximate change in the Sharpe Ratio from adding the country index to the benchmark assets. Spanning weights (that sum to one) are given for the tests using the index of fund price returns 
Notes (Table 6):

\section{Panel 2}

$E\left[R_{t+1}^{P}\right]$ and $E\left[R_{i+1}^{N}\right]$ are computed according to equation (11) in the text using the discount factor that prices the six value-weighted country fund indices. $\Delta$ is the difference between expected price and NAV returns. It represents the cost, in terms of a reduction in expected return, that investors would be willing to accept in exchange for direct access to the assets of the funds.

To compute standard errors for $\Delta$ and the expected returns, we first derived the GMM variance-covariance matrices for $b_{11}$ (see Section 3.2) and the covariance between benchmark returns and price and $N A V$ returns for the six countries. Denote the latter moment estimates as $C O V$. Since the expected returns and $\Delta$ are a function of $b_{11}$ and $C O V$, the mean value theorem was applied to derive their standard errors. We assumed a block-diagonal structure for the variance-covariance matrix of $b_{11}$ and $C O V$.

Mean (.) denotes the time series average of returns.

All expected return measures arr multiplied by 5200 . 
Table 7

Stock Market Characteristics and Investment Restrictions

\begin{tabular}{|c|c|c|c|c|c|c|}
\hline Measure & Indonesia & Korea & Philippines & Taiman & Thailand & Turkey \\
\hline Market Cap & 14385.0 & 94289.7 & 14077.1 & 124818.0 & 48252.4 & 11291.1 \\
\hline $\begin{array}{c}\text { Market Cap/ } \\
\text { GDP } \\
\end{array}$ & 0.09 & 0.25 & 0.17 & 0.32 & 0.35 & 0.12 \\
\hline Turnover & N.A. & 123.19 & 22.19 & 192.80 & 149.25 & 72.68 \\
\hline $\begin{array}{c}\text { Percent } \\
\text { Investable }\end{array}$ & 47.6 & 9.6 & 47.3 & 3.0 & 27.0 & 97.3 \\
\hline $\begin{array}{c}\text { Exchange } \\
\text { Rate Regime }\end{array}$ & $\begin{array}{c}\text { Managed } \\
\text { Floa! }\end{array}$ & $\begin{array}{l}\text { Pegged } \\
\text { to Dollar }\end{array}$ & $\begin{array}{l}\text { Free } \\
\text { Float }\end{array}$ & $\begin{array}{c}\text { Managed } \\
\text { Float }\end{array}$ & $\begin{array}{c}\text { Pegged } \\
\text { to Basket }\end{array}$ & $\begin{array}{l}\text { Free } \\
\text { Float }\end{array}$ \\
\hline $\begin{array}{l}\text { \# Country } \\
\text { Funds }\end{array}$ & 12 & 16 & 5 & 10 & 17 & 2 \\
\hline $\begin{array}{c}\text { \# ADR } \\
\text { Programs }\end{array}$ & 1 & 6 & 7 & 5 & 5 & 3 \\
\hline $\begin{array}{l}\text { Credit } \\
\text { Rating }\end{array}$ & 50.5 & 67.6 & 25.2 & 77.5 & 61.3 & 43.9 \\
\hline $\begin{array}{c}\text { Infation } \\
\text { Variability }\end{array}$ & N.A. & 6.3 & 9.0 & N.A. & 5.8 & 28.0 \\
\hline
\end{tabular}

Notes:

Market Cap is the average dollar market capitalization of the local market index for each country, in millions (see the Data Appendix for specific indices). Turnover is the annual value of traded local stocks divided by Market Cap. GDP data are taken from the IMF International Financial Statistics, except for Tawan. For Taiwan, GNP obtained from its Central Bank Annual Report is substituted for GDP. The Market Cap, Turnover and GDP data are measured in 1992, approximately the middle of our sample, except for Indonesia's Market Cap, which is measured in March 1993.

Percent Investable is the ratio of the IFC Investable index, which controls for foreigu ownership restrictions, and the IFC Global index. Figures are taken from the IFC Indcx Methodology in March, 1993. Section 2 describes the indices.

The Exchange Rate Regime is taken from the 1994 IMF Annual Report on Exchange Agreements and Exchange Restrictions.

\# Country Funds and \# ADR Programs is taken from Table 6 in Bekaert, Garcia and Harvey [1994]. Only publically-traded country funds focusing on the target market are included. 


\section{Nates (Table 7):}

The Credit Rating is taken from Institutional Investor, March 1992. A value of 100 represents a perfect credit rating.

Inflation Variability is the standard deviation of monthly rates, taken from the $I M F$ International Financial Statistics for the period 1986-1992, multiplied by 1200 .

N.A. indicates the number is not available. 
Table 8

Mean-Variance Spanning and Investment Liberalizations

December 1989 - August 1993

\begin{tabular}{|c|c|c|c|}
\hline \multirow[b]{2}{*}{ Test Asset 8} & \multicolumn{3}{|c|}{ p-value [ Change in Sharpe Ratio] } \\
\hline & {$\left[\widetilde{\beta_{21}}, \widetilde{\beta_{22}}\right]=0$} & Before Liberalized & After Liberalized \\
\hline \multirow[t]{2}{*}{$\mathrm{BZF}$} & 0.6512 & 0.6631 & 0.7563 \\
\hline & & {$[0.0032]$} & {$[0.0021]$} \\
\hline \multirow[t]{2}{*}{ IGF } & 0.2719 & 0.2503 & 0.9731 \\
\hline & & {$[0.0009]$} & {$[0.0008]$} \\
\hline \multirow[t]{2}{*}{ KF } & 0.3229 & 0.2722 & 0.0176 \\
\hline & & {$[0.0242]$} & {$[0.0002]$} \\
\hline \multirow[t]{2}{*}{ TWX \& ROC Indrx } & 0.1116 & 00082 & 0.5085 \\
\hline & & {$[0.0040]$} & {$[0.0003]$} \\
\hline
\end{tabular}

Notes:

Information on restricted markets was obtained from Bekaert [1994] and the IFC IndeI Methodology, 1993.

Country funds normally receive special permission to trade in the securities of restricted markets before the markets are opened to all foreign investors. Foreign institutions in addition to country funds ware granted accese in 49 percent of voting common stock in Brazil in May 1991. In January 1092. foreign investors were allowed to acquire up to 10 percent of horean company securities. In January 1991, foreign investors were granted permission to hold 10 percent of Taikanese company securities. India opened to foreign investors in November, 1992, with a 25 percent cap on holdings by registered foreign institutions. A variety of overriding restrietions apply in all cases. The test period begins in December 1989

The hypothesis, $\left[\widetilde{\beta_{21}}, \widetilde{\beta_{22}}\right]=0$, is tested using a GMM Wald statistic. The mean-variance spanning hypothesis before and after the liberalization is tested using the statistic $M V_{3}$. The p-value is the probahility value. See Section 3.2 or the Appendix for details. Numbers in square brackets indicate the approximate change in the Sharpe Ratio from adding the test assets to the benchmark assets.

All returns are computed in dollars, and all indices are equally-weighted. The benchmark assets are the closed-end fund mature market and domestic indices. 


\section{Appendix}

\section{A A GMM-Based Wald Test of Mean-Variance Span- ning}

Huberman and Kandel [1987] define mean-variance spanning in a linear regression model. Let $R_{t}^{1}$ denote a vector of benchmark asset returns. To test whether these returns span the vector of returns $R_{t}=\left[R_{t}^{1 \prime}, R_{t}^{2 \prime}\right]^{\prime}$, consider the linear regression:

$$
R_{\imath}^{2}=\alpha+B R_{\imath}^{1}+u_{\imath}
$$

Huberman and Kandel show that testing for spanning of $R_{t}$ by $R_{t}^{1}$ is equivalent to testing:

$$
\alpha=0 \quad B \iota=\imath
$$

with $i$ a vector of ones.

In this appendix, we will first write the De Santis test in an alternative way to prepare for the derivation of the Wald tect. Since these GMM-based tests seem very different from the standard Huberman and Kandel [198i] tests, we then demonstrate how the Wald test and the Huberman and Kandel test are tests of particular restrirtions on the first and secons moments of $R_{t}=\left[R_{t}^{1 \prime}, R_{t}^{2 \prime}\right]^{\prime}$. A similar derivation can be found in Ferson [1993].

The orthogonality conditions for the De Santis test are given in equation (7) in the text. As above, let $R_{t}=\left[R_{t}^{\prime \prime}, R_{t}^{2 \prime}\right]^{\prime}$ and let the dimension of $R_{t}^{1}\left(R_{t}^{2}\right)$ be $n_{1}\left(n_{2}\right) \times 1$. Denole. $n=n_{1}+n_{2}$. Let $\beta$ be a $2 n \times 1$ vector. The orthogonality conditions for the Wald test can be written as:

$$
h_{T}(\beta)=C_{T} \beta+d_{T}
$$

where the dimensionality of $h_{T}$ is $2 n \times 1$ and $C_{T}$ is a square matrix. Hence,

$$
\beta=-C_{T}^{-1} d r
$$

Let $A$ be a $2 n_{2} \times 2 n$ matrix that selects the elements of the $2 n \times 1$ vector $\beta$ that are zern under the null of spanning. When the weigthing matrix in the GMM-system, $W_{T}$, is chosen 
optimally (Hansen [1982]), the variance-covariance matrix of $\beta$ equals $\left(C_{T} W_{T}^{\prime} C_{T}^{\prime}\right)^{-1}$. The expression for the Wald test in equation (9) in the text follows straightforwardly.

The De Sant is test is nothing more than a likelihood ratio-type test which requires estimation under the null. It is useful to think about the De Santis test as arising from a restricted estimation. Let $\tilde{\beta}$ denote the restricted estimator of $\beta$ (i.e., with the zero restriction on thr coefficients of the test assets imposed). Then,

$$
\begin{aligned}
& j= \underset{j}{\operatorname{argmin}} h_{T}(\beta)^{\prime} W_{T} h_{T}(\beta) \\
& \text { s.t. } \quad A \beta=0 \\
& h_{T}(\beta)= C_{T} \beta+d_{T} .
\end{aligned}
$$

Note that the orthogonality conditions are linear in the parameters and so is the constraint. Consequently, Proposition 4 in Newey and West [1986] implies that the Wald test and thr likelihood ratio-type test are numerically equivalent. Denote the De Santis test statistic by $L$. It is given by:

$$
L=T h_{T}(\tilde{\beta})^{\prime} W_{T} h_{T}(\tilde{\beta})
$$

Of course, the equivalence relies on the use of the same weighting matrix. As our Montc Carlo results show, the choice of the weighting matrix is one important determinant of the small sample properties of the test statistics.

Finally, let's consider the moment restrictions implied by mean-variance spanning tests. We will first rewrite the spanning restrictions derived by Huberman and Kandel [19:5]. reproduced in equation (2). Let $\mu_{1}$ denote $E\left[R_{t}^{1}\right]$ and let $\mu_{2}$ denote $E\left[R_{t}^{2}\right]$. Using leasi squares algebra, the restrictions in equation (2) are equivalent to:

$$
\begin{array}{r}
\mu_{2}-\Sigma_{R}^{12}\left(\Sigma_{R}^{11}\right)^{-1} \mu_{1}=0 \\
\Sigma_{R}^{12}\left(\Sigma_{R}^{11}\right)^{-1} \iota=\iota .
\end{array}
$$

where $\sum_{R}$ is the covariance matrix of the set of returns $R_{t}=\left[R_{t}^{1 \prime}, R_{t}^{2 \prime}\right]^{\prime}$, partitioned as:

$$
\Sigma_{R}=\left[\begin{array}{ll}
\Sigma_{R}^{11} & \Sigma_{R}^{12} \\
\Sigma_{R}^{21} & \Sigma_{R}^{22}
\end{array}\right]
$$


The Wald test, on the other hand, implies:

$$
A \hat{b}=0=-A C_{T}^{-1} d_{T}
$$

Recall the expressions for $C_{T}$ and $d_{T}$ (see equation (7) in the text):

$$
\begin{aligned}
C_{T} & =\left[\begin{array}{cc}
\sum_{R} & 0 \\
0 & \sum_{R}
\end{array}\right] \\
d_{T} & =\left[\begin{array}{l}
\alpha_{1}(\mu+\iota)-\iota \\
\alpha_{2}(\mu+\iota)-\iota
\end{array}\right],
\end{aligned}
$$

where $\mu=\left[\mu_{1}^{\prime}, \mu_{2}^{\prime}\right]^{\prime}$.

Using (10) and the partitioned inverse formula in (9), we find:

$$
\Sigma_{R}^{21}\left(\Sigma_{R}^{11}\right)^{-1}\left[\left(\mu_{1}+\iota\right) \alpha_{j}-\iota\right]=\left(\mu_{2}+\iota\right) \alpha_{j}-\iota
$$

for $j=1,2$.

This can only be true for both $j=1$ and $j=2$ if the Huberman-Kandel restrictions proposed in equation (7) hold. 


\section{B Monte Carlo Experiments}

The Date Generating Process (DGP) for the returns $\left[R_{t}^{1}, R_{t}^{2}\right]$ under the null of mean variance spanning is assumed to be:

$$
\begin{aligned}
& R_{t}^{1}=\mu+A R_{t-1}^{1}+\epsilon_{t} \\
& R_{t}^{2}=B R_{t}^{1}+u_{t}
\end{aligned}
$$

$$
\text { s.t. } B \iota=\imath \text {. }
$$

The restriction $B \iota=\iota$ imposes mean variance spanning (sce Appendix A). Let

$$
\begin{aligned}
& \epsilon_{t} \sim N\left(0, \Sigma_{t}\right) \\
& u_{t} \sim N\left(0, \Sigma_{u}\right),
\end{aligned}
$$

where $\sum_{t}$ follows a constrained correlation GARCH-model (Bollerslev [1991]), or

$$
\begin{array}{cc}
\Sigma_{t}^{i i}= & w_{i}+\alpha_{i}\left(\epsilon_{t-1}^{i}\right)^{2}+\beta_{i} \Sigma_{t-1}^{i i} \\
i=1 \ldots, n_{1} \\
\Sigma_{t}^{i j}= & \rho_{i} \Sigma_{t}^{i i} \Sigma_{t}^{j j}, \quad i \neq j,
\end{array}
$$

where the superscripts indicate the position in the matrix or vector.

The parameter vector $\left[\mu^{\prime}, v e c(A)^{\prime}, v e c(B)^{\prime}, v e c h\left(\Sigma_{u}\right)\right]^{\prime}$ is estimated from our data set using GMM. We use the residuals $\epsilon_{t}$ to estimate the multivariate GARCH model in equation (3). In the estimation of (3), we constrain $w_{i}$ to match the unconditional sample variance of $\epsilon_{i}^{i}$. i.e., we let:

$$
u_{i}=\frac{\frac{1}{T} \Sigma\left(\epsilon_{i}^{i}\right)^{2}}{1-\alpha_{i}-\beta_{i}} .
$$

We consider two sets of four benchmark returns (see Section 3.3). Hence, the number of parameters to be estimated in the multivariate GARCH process becomes 14 under the null. When no ARCH effects were found for residual $i$, the estimation was redone constraining $\alpha_{i}=\beta_{i}=0$. So the returns $\left[R_{t}^{1}, R_{t}^{2}\right]$ have time-varying conditional means and variances. but the mean and variance dynamics for $R_{t}^{2}$ are completely driven by $R_{i}^{1}$. Estimation wa performed using the MAXLIK package in GAUSS. 
Under the null of mean variance spanning, all test statistics have a $\chi^{2}$ distribution with $2 n_{2}$ degrees of freedom. The choice of $n_{2}$ is guided by our empirical work. We set $n_{2}=1$. $n_{2}=2, n_{2}=7$ and $n_{2}=12$, to correspond to the dimension of the test assets described in Section 3.3 of the text. ${ }^{1}$

Table A1 reports the percentage of the 2,000 experiments constructed under the null hypothesis for which the values of the test statistics are greater than the five percent critical values of the null distribution. A standard error for the empirical size can be computed as

$$
\left[\frac{(0.05)(0.95)}{2,000}\right]^{1 / 2}=0.0049 \text {. }
$$

The table shows that the size properties of the statistics are very different. First of all, demeaning the orthogonality conditions (compare $M V_{2}$ to $M V_{1}$ and $M V_{4}$ to $M V_{3}$ ) invariably: worsens the size distortion. Srcond, a serial correlation correction leads to an empirical size close to $5 \%$, only if the orthogonality conditions are not de-meaned. That is, $M \mathrm{~V}_{3}$ performs better than $M V_{1}$ but $M V_{2}$ performs better than $M V_{1}$. Note that by using the optimal bandwidth scheme of Andrews [1991], the serial correlation correction may not always be applied. The use of a fixed number of Newey-West [1987] lags would probably lead to inferior size properties. Iterating on the weighting matrix marginally improves the size properties of the test. The Wald statistic with no serial correlation correction, $M V_{W_{2}}$, performs better than $M V_{W_{1}}$, but the size properties are poor when compared with $M V_{3}$.

For $n_{2}=1$ and $n_{2}=2$, all test statistics perform reasonably well, and the empirical sizes of $M V_{1}, M V_{3}$ and $M V_{W^{\prime}}$ are within two standard error bands around the nominal size. For $n_{2}=7$. the size distortions become problematic for most test statistics and the superior small sample behavior of $M V_{3}^{\prime}$ stands out. We conclude that $M V_{3}$, the test statistic with a serial correlation correction and the orthogonality conditions not de-meaned, gives the leas $t$ small sample distortion.

We also examine the power of the tests. In order to do so, we need to formulate a DGP under an alternative hypothesis. To make the alternative easy to interpret, we let the benchmark assets follow the same process as under the null. The new factor is assumed independent of the old factors and follows a univariate $\mathrm{AR}(1)$ process. Its error terms are

\footnotetext{
${ }^{1}$ We did not perform the Monte Carlo analysis for $n_{2}=19$. As will become clear, the test statistics arr likely to be ill-behaved for such a large number of test assets.
} 
normally distributed with the conditional variance following a GARCH $(1,1)$ process. To estimate parameters for this process, we use the IFC Investable Composite index return as a proxy for emerging market-specific risk (Section 2 describes this index).

Finally, we have to determine the new matrix $B$. For each return in $R_{t}^{2}$, the corresponding row in the $B$ matrix can be interpreted as the portfolios weights on the different benchmark assets that span it. Indeed, the weights sum to one but they need not be positive. For each test asset, we choose the new weights starting from the matrix $B$ under the null, but redistribute some of each weight (say $y$ ) from the original benchmark assets to the new benchmark asset. Hence, the wejght on the new benchrnark asset becomes $4 y$, since there are four benchmark assets under the null. The redistribution is such that the proportion of test asset variance explained by the new benchmark is $20 \%$ higher than the proportion explained by the benchmark under the null. Note that this is not a particularly strong alternative. If the $R^{2}$ were $30 \%$ under the null, our alternative implies an increase in $R^{2}$ to $36 \%$. In the actual data, including the IFC Investable Composite index in a regression of country funds indices onto the null benchmark assets increases the $R^{2}$ by $40 \%$ rather than $20 \%$.

In order to prevent the implied weights on the new factor from becoming too large, wr had to scale up its variance by a factor of 3 . The resulting variance is of the same magnitude as that of the individual country fund with the lowest sample variance in our sample. The implied weights on the new benchmark asset vary between 0.26 and 0.66 .

To summarize the DGP under the alternative, let $R_{t}^{e}$ denote the new benchmark return. and define $\overline{R_{t}^{1}}=\left[R_{t}^{1 \prime}, R_{t}^{e}\right]^{\prime}$. Then,

$$
\begin{aligned}
\overline{R_{t}^{1}} & =\bar{\mu}+\bar{A} \overline{R_{t-1}^{1}}+\overline{\epsilon_{t}} \\
\overline{R_{t}^{2}} & =\bar{B} \overline{R_{t}^{1}}+\overline{u_{t}} \\
& \text { s.t. } \bar{B} \iota=\iota,
\end{aligned}
$$

with

$$
\bar{\mu}=\left[\begin{array}{c}
\mu \\
\mu^{e}
\end{array}\right] \quad \bar{A}=\left[\begin{array}{cc}
A & 0 \\
0 & a^{e}
\end{array}\right] \quad \bar{\Sigma}_{c}=\left[\begin{array}{cc}
\Sigma_{e} & 0 \\
0 & \left(\sigma^{e}\right)^{2}
\end{array}\right] .
$$

The way we construct $\bar{B}$ implice that $\bar{B}=[B-b / 4, b]$, where $b$ is a $n_{2} \times 1$ vector containing the weights on the new factor. It turns out that in order to satisfy the explained varianer 
criterion, each element in $b$ must satisfy a quadratic equation with two real roots. We take $b_{1}, \forall i$ to be the positive root of this equation. ${ }^{2}$

The power of the test statistics hovers around $70 \%$ for $n_{2}=1$ and $n_{2}=2$, and drops below $50 \%$ for most test statistics when $n_{2} \geq 7$. For $n_{2}=12$, the null and alternative distributions are quite close to each other. The $M V_{3}$ statistic - the test with the best small size properties - has the worst power for $n_{2}=12$, but not for smaller $n_{2}$. The Wald tests seem to have poor power properties in general compared with the likelihood ratio-type tests. To maximize power, orthogonality conditions should be de-meaned but serial correlation corrections should be avoided as is demonstrated by the superior performance of $M V_{2}$.

In general, both the size and power properties seem to deteriorate substantially as thr number of assets is increased. We conjecture that the saturation ratio (see Gallant and Tauchen [1991]) of the GMM system is the driving factor in the results. The saturation ratio is the total number of observations divided by the number of parameters to be estimated (including the parameters of the weighting matrix). When $n_{2} \geq 7$, the saturation ratio drops below 10. Unfortunately. GMM-systems with such low saturation ratios are common in the empirical finance literature. To conclude, $M V_{3}$ has significant superior size properties relative to the other test statistics. Although it has poor power for $n_{2}=12$, its power does not differ substantially from that of the other statistics for smaller systems. ${ }^{3}$ Therefore. we use $M V_{3}$ for all our tests with the caveat that all the tests perform poorly when the saturation ratio is low:

\footnotetext{
${ }^{2}$ Another potentially interesting alternative would let $\overline{u_{t}}$ be serially correlated but keep the number of benchmark assets intact. We intend to explore the power of our tests against such an alternative in thr. future. We also plan to investigate the small sample properties of alternative mean variance spanning tests (Huberman and Kandel [198i], Jobson and Korkie [1989], and Ferson et al. [1993] are examples).

${ }^{3}$ In weighing the relative advantages and disadvantages of the various test statistics, power shonld be the. more important consideration, especially since our alternative (exposure to an 'emerging market factor") is an economically interesting one. See McCloskey [1985] for a critique on the misuse of "significance tests" and their lack of power, and other considerations in hypothesis testing by economists.
} 


\section{Data Appendix}

For each country fund, the sample contains weekly price, NAV, exchange rate, dividend, and volume information for the life of the fund. For the U.K. trusts, 'diluted' NAV and warrant prices are also included. The price, dividend and volume data was obtained daily from the CRSP database for U.S. funds; NAV information was obtained weekly from Barrons and Thr Wall Street Journal, and daily for several funds from Scudder, Stevens and Clark. County Natwest Securities supplied the weekly price, NAV and diluted NAV numbers for the U.K. funds, and S.G. Warburg provided daily price, diluted NAV, warrant prices, and volume. Dates for individual fund coverage are given in Table 2.

For the emerging market funds we use three weekly total return dollar indices compiled for the Emerging Markets Data Base (EMDB) maintained by the IFC. They are a local market index, the IFC Global index, and the IFC Investable index. Weekly coverage for the IFC indices begins in December 1988. As there are some exceptions in coverage, the adjoining table details the date when the series begins for each of the three IFC indices. The table also indicates the name of the local market index. For the emerging markets we obtained weekly exchange rate data from the IFC, and daily rates from Tradeline International. Local market and regional total return indices and exchange rates for the mature markets were provided by Goldman, Sachs \& Co.; for the mature markets represented in our sample, daily coverage begins in January, 1986.

The database also includes information on capital changes, warrant exercise, the composition of dividend payments, and missing values for each fund. Missing values are only a problem for the U.S. NAV scries for a few funds. In cases where we were unable to complets the series using alternate sources, we used the previous week's figure.

In constructing weekly fund data, the correct U.S. price was paired with the weekly NAY data, which normally is computed on Friday, but also Wednesday or Thursday in several cases. Where possible the timing of indices was matched to the price and NAV information. A similar procedure was followed to construct weekly U.K. files from daily series.

Seven-day deposit LIBOR rates in dollars and pounds were obtained from Bloombers and The Financial Times of London. 
Market Indices for Emerging Equity Markets

Through August 1993

\begin{tabular}{|c|c|c|c|c|}
\hline Country & \multicolumn{2}{|c|}{ Local Index } & IFC Global & IFC Investable \\
\hline \multicolumn{5}{|c|}{ Latin America } \\
\hline Argentina & Bolsa Indice & 881230 & 881230 & 881230 \\
\hline Brazil & BOVESPA & 880331 & 881230 & 881230 \\
\hline Chile & IGPA & 881230 & 881230 & 881230 \\
\hline Mexico & BMV General & 881230 & 881230 & 881230 \\
\hline \multicolumn{5}{|c|}{ Asia } \\
\hline India & FE Bombay & 881230 & 881230 & 921106 \\
\hline Indonesia & JSE Compositc & 881230 & 900928 & 900928 \\
\hline Korea & KSE Composite & 860102 & 881230 & 920103 \\
\hline Malaysia & KLSE Composite & 881230 & 881230 & 881230 \\
\hline Philippines & Manila Com/Ind & 881230 & 881230 & 881230 \\
\hline Taiwan, China & TSE Average & 881230 & 881230 & 910104 \\
\hline Thailand & SET & 881230 & 881230 & 881230 \\
\hline \multicolumn{5}{|c|}{ Europe/Mideast } \\
\hline Portugal & BTA & 881230 & 881230 & 881230 \\
\hline Turkey & ISE & 881230 & 881230 & 890804 \\
\hline
\end{tabular}

Notes:

All indices are taken from the Emerging Markets Data Base. Supplemental dates for the KSE Composite were obtained from the KSE Fact Book and for the BOVESPA from the Sao Paulo Stock Exchangr. 
Table A1

Empirical Size of Test Statistics

\begin{tabular}{|lrrrr|}
\hline \multicolumn{5}{c|}{ Panel 1: } \\
\hline \multicolumn{5}{c|}{ Closed-End Fund Benchmark Assets } \\
\hline$\chi^{2}(2)$ & $\chi^{2}(4)$ & $\chi^{2}(14)$ & $\chi^{2}(24)$ \\
$M V_{1}$ & 5.55 & 5.80 & 10.45 & 16.80 \\
$M V_{2}$ & 6.00 & 7.15 & 17.30 & 36.65 \\
$M V_{3}$ & 5.60 & 4.80 & 7.55 & 6.60 \\
$M V_{4}$ & 8.00 & 9.40 & 26.30 & 53.15 \\
$M V_{5}$ & 7.65 & 8.90 & 22.70 & 48.05 \\
$M V_{W_{1}}$ & 7.00 & 7.90 & 19.40 & 40.90 \\
$M V V_{w_{2}}$ & 5.95 & 5.95 & 12.30 & 26.05 \\
\hline$C V\left(\chi^{2}\right)$ & 5.99 & 9.49 & 23.69 & 36.42 \\
$C V\left(M V_{3}\right)$ & 6.25 & 9.42 & 25.20 & 37.57 \\
\hline
\end{tabular}

Panel 2:

FT-Actuaries World Indices Benchmark Assets

\begin{tabular}{|lrrrr|}
\hline & $\chi^{2}(2)$ & $\chi^{2}(4)$ & $\chi^{2}(14)$ & $\chi^{2}(24)$ \\
\hline$M V_{1}$ & 5.85 & 7.00 & 10.45 & 13.05 \\
$M V_{2}$ & 6.10 & 8.00 & 17.35 & 34.15 \\
$M V_{3}$ & 5.85 & 6.50 & 9.25 & 7.30 \\
$M V_{4}$ & 6.50 & 8.90 & 21.80 & 45.40 \\
$M V_{5}$ & 6.45 & 8.50 & 19.30 & 41.60 \\
$M V_{1}$ & 6.30 & 7.80 & 16.15 & 33.55 \\
$M V_{2}$ & 6.15 & 7.00 & 12.85 & 23.85 \\
\hline$C V\left(\chi^{2}\right)$ & 5.99 & 9.49 & 23.69 & 36.42 \\
$C V\left(M V_{3}\right)$ & 6.27 & 10.01 & 26.06 & 38.57 \\
\hline
\end{tabular}

\section{Notes:}

The empirical size (in percent) is for a $5 \%$-size test. The test statistics and Monte Carlo design are described in the text. The benchmark assets are further described in Section 3.3. In the column heading $" \chi^{2}(n), " n / 2$ is the number of test assets used. The experiment for $n=2$, uses a U. S. index of country funds. The results for U. K. indices are similar. $C V$ stands for critical value. We report the $5 \%$ critical value for each $\chi^{2}$-distribution and for the empirical distributions generated for the $M V_{3}$ test statistic. 
Table A2

Power of Test Statistics

\begin{tabular}{|ccccc|}
\hline \multicolumn{5}{c|}{ Panel 1: } \\
\hline \multicolumn{5}{c|}{ Closed-End Fund Benchmark Assets } \\
\hline$M V_{1}$ & 71.50 & 74.80 & 49.85 & 19.85 \\
$M V_{2}$ & 71.70 & 75.15 & 52.45 & 27.95 \\
$M V_{3}$ & 68.45 & 71.90 & 46.05 & 13.10 \\
$M V_{4}$ & 68.35 & 71.50 & 44.65 & 21.00 \\
$M V_{3}$ & 67.95 & 71.05 & 41.30 & 20.60 \\
$M V_{W^{\prime} 1}$ & 65.80 & 70.10 & 36.75 & 14.80 \\
$M V_{W^{\prime} 2}$ & 71.35 & 72.30 & 40.10 & 17.95 \\
\hline
\end{tabular}

\section{Panel 2:}

FT-Actuaries World Indices Benchmark Assets

\begin{tabular}{|lrrrr|}
\hline & $\chi^{2}(2)$ & $\chi^{2}(4)$ & $\chi^{2}(14)$ & $\chi^{2}(24)$ \\
\hline$M V_{1}$ & 73.15 & 70.00 & 51.75 & 19.45 \\
$M V_{2}$ & 73.15 & 70.85 & 54.00 & 27.85 \\
$M V_{3}$ & 72.25 & 69.50 & 46.75 & 13.30 \\
$M V_{4}$ & 73.10 & 70.00 & 49.10 & 26.85 \\
$M V_{5}$ & 72.50 & 69.30 & 47.15 & 25.00 \\
$M V_{\text {W }}$ & 70.75 & 67.15 & 39.35 & 17.60 \\
$M V_{W 2}$ & 71.40 & 42.75 & 18.85 & 13.55 \\
\hline
\end{tabular}

\section{Notes:}

The test statistics and the DGP under the alternative are described in the text. The benchmark assets are further described in Section 3.3. In the column heading " $\chi^{2}(n)$." $n / 2$ is the number of test assets used. The experiment for $n=2$, uses a U. K. index of country funds. The power using the U.S. index is slightly lower. The table reports the percent of 2,000 Monte Carlo replications that yield a higher test statistic than the $5 \%$ critical value from the empirical distribution under the null. 
FIGURE ।

Unconditional Mean-Voriance Spanning: $\Pi$-Acluories Benchmork
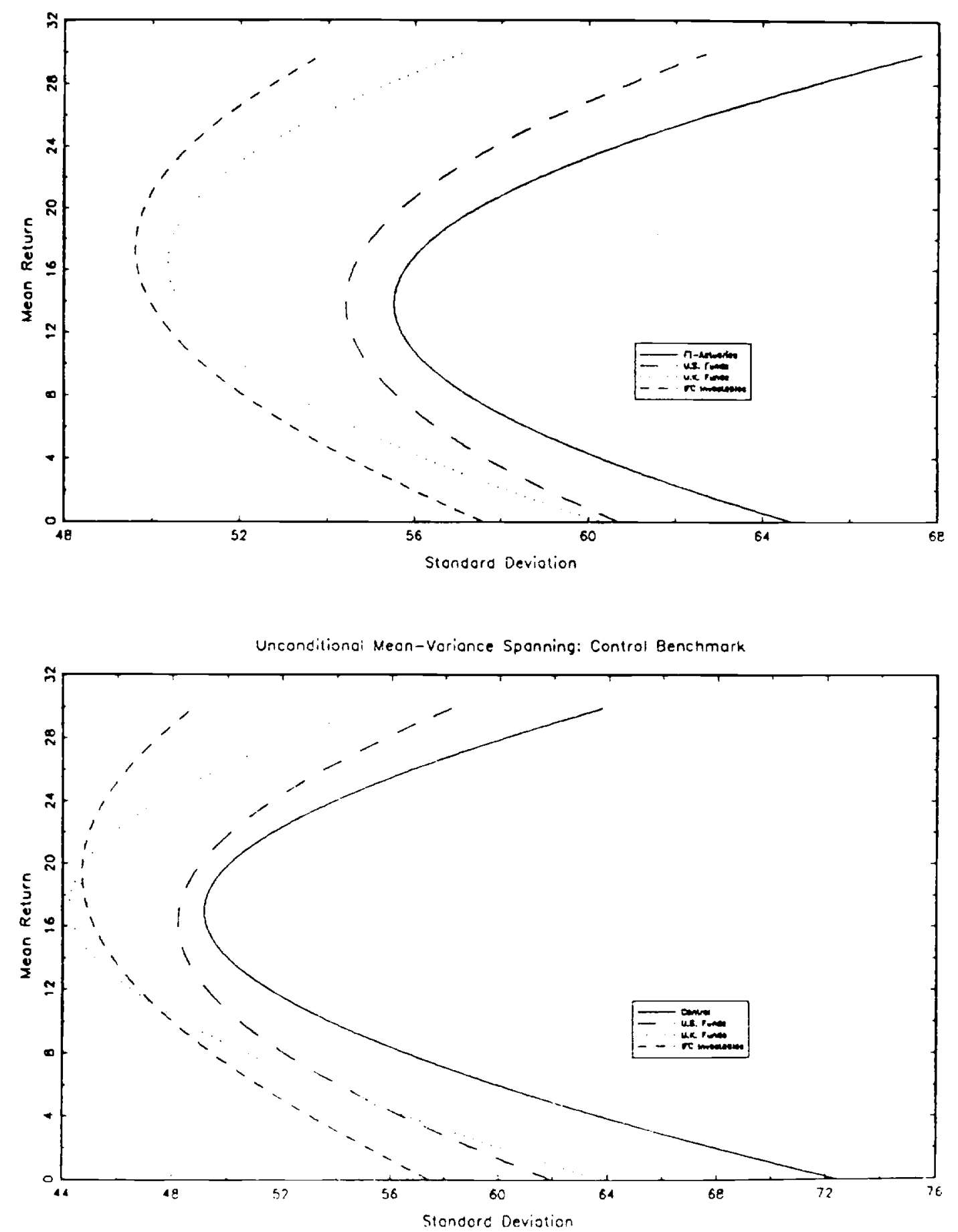